Prepared for the U.S. Department of Energy under Contract DE-AC05-76RL01830

\title{
Self-Correcting HVAC Controls Project Final Report
}

N Fernandez

MR Brambley

S Katipamula

H Cho

J Goddard

L Dinh

December 2009

Pacific Northwest

NATIONAL LABORATORY

Proudly Operated by Battelle Since 1965 


\title{
DISCLAIMER
}

This report was prepared as an account of work sponsored by an agency of the United States Government. Neither the United States Government nor any agency thereof, nor Battelle Memorial Institute, nor any of their employees, makes any warranty, express or implied, or assumes any legal liability or responsibility for the accuracy, completeness, or usefulness of any information, apparatus, product, or process disclosed, or represents that its use would not infringe privately owned rights. Reference herein to any specific commercial product, process, or service by trade name, trademark, manufacturer, or otherwise does not necessarily constitute or imply its endorsement, recommendation, or favoring by the United States Government or any agency thereof, or Battelle Memorial Institute. The views and opinions of authors expressed herein do not necessarily state or reflect those of the United States Government or any agency thereof.

\author{
PACIFIC NORTHWEST NATIONAL LABORATORY \\ operated by \\ BATTELLE \\ for the \\ UNITED STATES DEPARTMENT OF ENERGY \\ under Contract DE-AC05-76RL01830
}

Printed in the United States of America
Available to DOE and DOE contractors from the
Office of Scientific and Technical Information,
P.O. Box 62, Oak Ridge, TN 37831-0062;
ph: (865) 576-8401
fax: (865) 576-5728
email: reports@adonis.osti.gov

\author{
Available to the public from the National Technical Information Service, \\ U.S. Department of Commerce, 5285 Port Royal Rd., Springfield, VA 22161 \\ ph: (800) 553-6847 \\ fax: (703) 605-6900 \\ email: orders@ntis.fedworld.gov \\ online ordering: http://www.ntis.gov/ordering.htm
}


PNNL-19074

\section{Self-Correcting HVAC Controls Project Final Report}

$\begin{array}{ll}\text { N Fernandez } & \text { H Cho } \\ \text { MR Brambley } & \text { J Goddard } \\ \text { S Katipamula } & \text { L Dinh }\end{array}$

December 2009

Prepared for

the U.S. Department of Energy

under Contract DE-AC05-76RL01830

Pacific Northwest National Laboratory

Richland, Washington 99352 


\section{Summary}

This document represents the final project report for the Self-Correcting Heating, Ventilating and Air-Conditioning (HVAC) Controls Project jointly funded by Bonneville Power Administration (BPA) and the U.S. Department of Energy (DOE) Building Technologies Program (BTP). The project, initiated in October 2008, focused on exploratory initial development of self-correcting controls for selected HVAC components in air handlers. The report, along with the companion report documenting the algorithms developed, Self-Correcting HVAC Controls: Algorithms for Sensors and Dampers in Air-Handling Units (Fernandez et al. 2009), document the work performed and results of this project.

The objective of the project was to develop and laboratory test algorithms that implement selfcorrection capabilities for sensors, economizer dampers, and damper actuators in building airhandling systems. Satisfaction of this objective led to 1) algorithms ready for implementation in or connected to building and equipment control systems for field demonstration and commercial application and 2) underlying methods that may be transferable to creating selfcorrecting capabilities for other heating, ventilating, and air-conditioning (HVAC) system components. Full-scale commercial deployment of this technology will capture significant energy savings by automatically eliminating many of the faults that degrade the efficiency of HVAC systems, thus maintaining energy efficiency well above the efficiency at which these systems routinely operate. Furthermore, to the extent that HVAC electricity use and system peaking are coincident (e.g., in the summer), peak demand will also be reduced by deployment of this technology.

Algorithms were developed for detecting, isolating, characterizing and correcting the following specific faults:

- biases in temperature and relative-humidity sensors in outdoor-, return- and mixed-air streams,

- an incorrectly set signal to position the outdoor-air damper of an air handler to meet the minimum ventilation requirements of the building while it is occupied,

- hunting (continuously oscillating) dampers, and

- controllers left in a state of manual control override that should be in an automatic control mode.

Laboratory tests for biased temperature and humidity sensors and incorrectly set values of the minimum occupied outdoor-air damper position signal showed that automatic self-correction of these faults can be successfully performed; however, under some conditions passive detection of the presence of a fault may not be possible, and the fault isolation process may reach an incorrect conclusion under some circumstances. The primary cause of incorrect conclusions in fault isolation were found to be caused by dampers leaking when completely closed. This problem can be addressed by modifying the algorithms to automatically account for imperfections in damper sealing, which is recommended.

Other recommendations for future work include: 
- other enhancements to the existing algorithms,

- additional laboratory testing to more completely characterize algorithm performance under a wide range of conditions and to better quantify the limits of fault detectability, isolation and correction,

- laboratory test additional algorithm capabilities not tested in the present project,

- development of self-correcting control algorithms for discharge-air temperature, humidity and static pressure control,

- develop self correcting control algorithms for additional HVAC equipment, such as air distribution, chilled- and hot-water distribution, cooling towers, etc.,

- study to quantify the benefits of deployment and use of self-correcting HVAC control technology for various systems,

- development of models for commercial deployment of the self-correcting HVAC technology, and

- other advancements that will contribute to rapidly developing and commercially deploying this promising technology. 


\section{Acknowledgments}

The work documented in this report was jointly supported by the Bonneville Power Administration and the Building Technologies Program of the U.S. Department of Energy. The authors wish to specifically thank Kacie Bedney, the Contract Officer's Technical Representative for the project from Bonneville Power Administration, and Alan Schroeder, Technical Development Manager at the Department of Energy for their support and guidance in the performance of this project. 


\section{Contents}

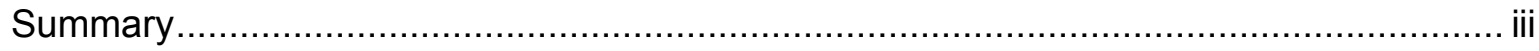

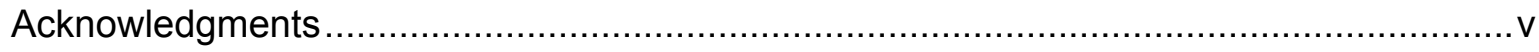

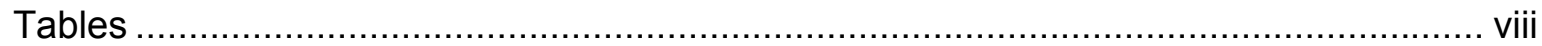

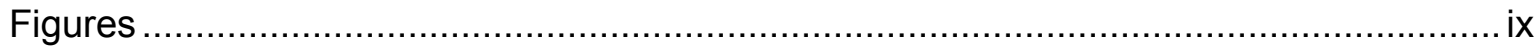

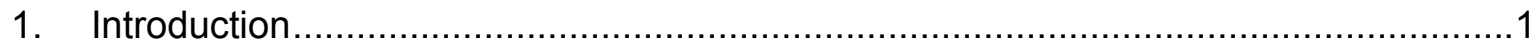

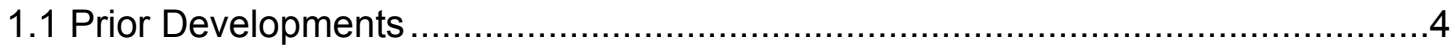

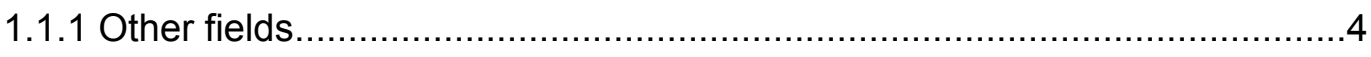

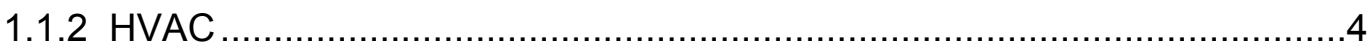

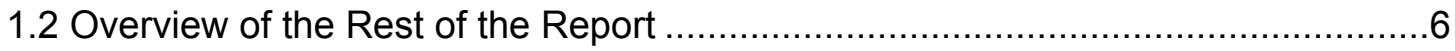

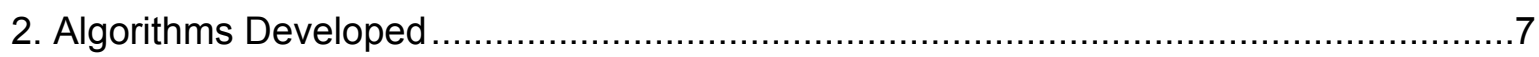

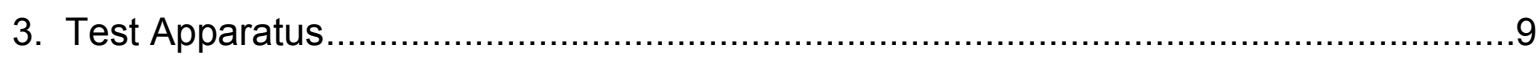

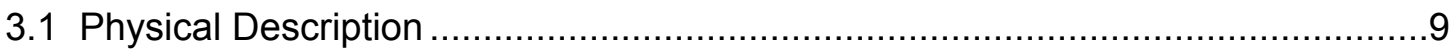

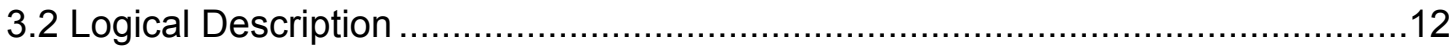

3.3 Using the Test Apparatus to perform SCC tests ........................................16

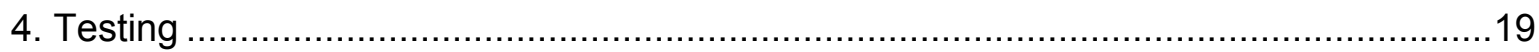

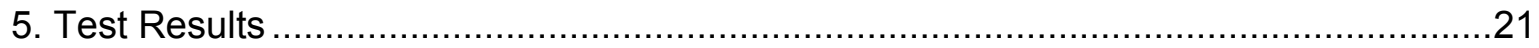

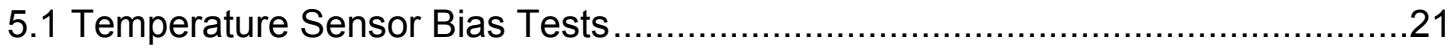

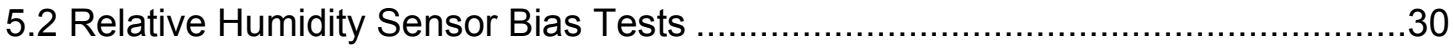

5.3 Minimum Occupied Damper Position Faults ........................................... 34

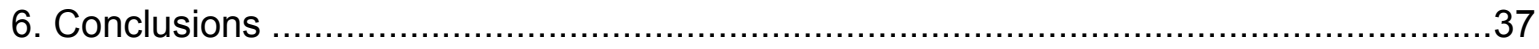

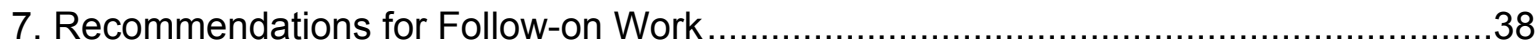

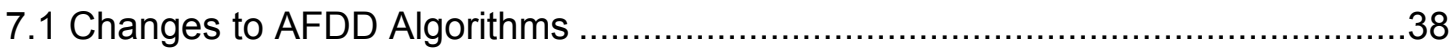

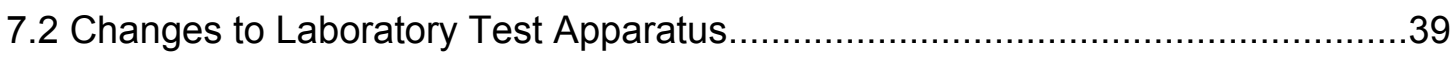

7.3 Testing Additional Faults Included in the Algorithm Set .................................39

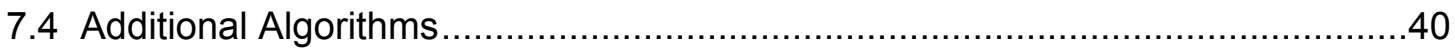

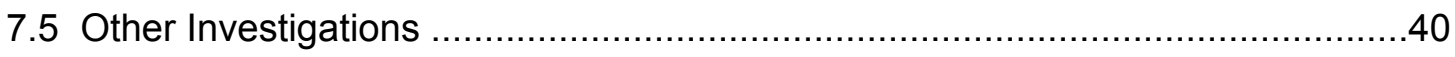

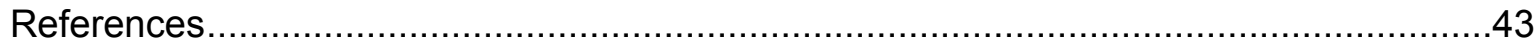


Appendix: Figures from Fernandez et al. 2009 45 


\section{Tables}

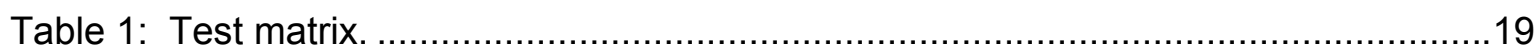

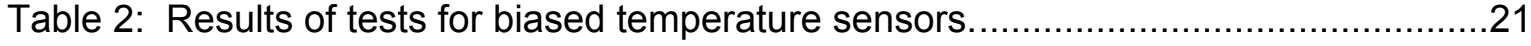

Table 3: Results of relative humidity sensor tests............................................. 31

Table 4: Test results for incorrectly set minimum occupied position..............................34

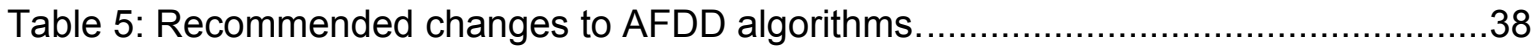




\section{Figures}

Figure 1: Diagram of test apparatus. Distances between components are not shown to scale.

Figure 2: Control system with web-based user control interface

Figure 3: Schematic diagram of the relationships among a sensor, controller and actuator for ordinary control (without correction) of a system.

Figure 4: Schematic diagram of a controlled system with a virtual sensor point added through which corrections to a faulty sensor signal can be implemented.

Figure 5: Diagram of system used to implement and correct faults using two virtual sensors.

Figure 6: System schematic showing supervisory fault detection, isolation, characterization and correction processes interfacing with the virtual sensor and controller.

Figure 7: Relationship between damper signal and OAF.................................. 17

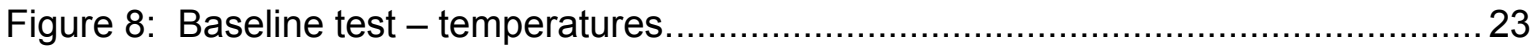

Figure 9: Baseline test - OAF and damper command. .............................................. 23

Figure 10: Test T-7-- detection, diagnosis and correction of a biased return-air temperature sensor.

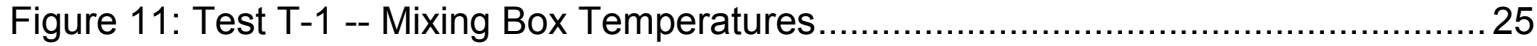

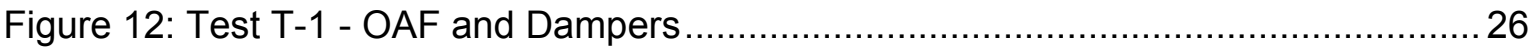

Figure 13: Intrinsic level of fault severity necessary to detect positive bias faults in $\mathrm{OA}$ temperature sensors using the minimum occupied position passive test.

Figure 14: Intrinsic level of fault severity necessary to detect negative bias faults in OA temperature sensors using the minimum occupied position passive test.

Figure 15: Intrinsic level of fault severity necessary to detect positive bias faults in RA temperature sensors using the minimum occupied position passive test.

Figure 16: Intrinsic level of fault severity necessary to detect negative bias faults in RA temperature sensors using the minimum occupied position passive test.

Figure 17: Intrinsic level of fault severity necessary to detect positive bias faults in MA temperature sensors using the minimum occupied position passive test.

Figure 18: Intrinsic level of fault severity necessary to detect negative bias faults in MA temperature sensors using the minimum occupied position passive test.

Figure 19: Test RH-2: Key variables for fault detection ..................................... 32

Figure 20: Test RH-3: Key variables for fault detection .......................................... 32 
Figure 21: Test $\mathrm{RH}-2$-- detection, diagnosis and correction for a $-20 \% \mathrm{RH}$ bias in the relative humidity sensor....

Figure 22: Damper position signal and OAF during Test MOP-3. 



\section{Introduction}

This document represents the final project report for the Self-Correcting Heating, Ventilating and Air-Conditioning (HVAC) Controls Project jointly funded by Bonneville Power Administration (BPA) and the U.S. Department of Energy (DOE) Building Technologies Program (BTP). The project, initiated in October 2008, focused on exploratory initial development of self-correcting controls for selected HVAC components in air handlers. This report, along with the companion report documenting the algorithms developed, Self-Correcting HVAC Controls: Algorithms for Sensors and Dampers in Air-Handling Units (Fernandez et al. 2009), document the work performed and results of this project.

Physical and control faults are common in HVAC equipment and systems, both built up and packaged. Today, large commercial buildings use sophisticated building automation systems (BASs) to manage a wide and varied range of building equipment. While the capabilities of BASs have increased over time, many buildings still do not fully use their capabilities. Furthermore, most commercial buildings are not properly commissioned, operated or maintained, which leads to inefficient operation, increased energy use, and reduced lifetimes of the equipment. Tuning BASs, much like tuning automobiles periodically, ensures maximum building energy efficiency and the comfort of building occupants. A poorly tuned system can and will maintain comfortable conditions but at a higher energy cost to overcome inefficiencies. If these systems can be enabled to self-correct and self-compensate for faults when encountered, HVAC equipment and systems would continue to operate efficiently until maintenance and repairs could be performed.

Packaged HVAC equipment is often maintained poorly with degradation of performance and faults only addressed when occupants complain or a unit fails to operate at all. Reactive maintenance of this sort leads to inefficient operation with high energy costs and significant waste. Allowing equipment to operate with faults also often leads to further physical deterioration of the equipment, reducing equipment lifetime, and sometimes complete and catastrophic failure.

Both built-up and packaged systems are frequently found with economizers that do not modulate dampers (Katipamula et al. 2003a, Lunneberg 1999); overridden automatic controls; valves that leak; simultaneous heating and cooling because both heating and cooling valves are open; excessive use of reheat during cooling because the temperature or static pressure set point for air leaving the air handlers is too low; air-conditioning systems that are improperly charged and operate with dirty filters and heat exchangers (Houghton 1997); and systems that are operated with failed or faulty sensors. It is also common for building systems to run 24-hours per day even though the building is unoccupied for many hours each day. These are a few of the common conditions found that cause substantial energy waste in our commercial building stock. Although there are no reliable nationwide or comprehensive Pacific Northwest data on the prevalence of such faults or energy impacts associated with inefficient operations, there is a general consensus that 10 to $30 \%$ of the energy is being wasted (Ardehali and Smith 2002, 
Ardehali et al. 2003, Brambley et al. 2005a and b, Breuker and Braun 1999, Claridge et al. 1996, Jacobs 2003, Mills et al. 2004).

Although monitoring and automated diagnostic tools can increase the awareness of building operators, owners, and HVAC service providers to the presence of operation faults in HVAC systems and equipment, information alone does not correct these faults. Action is required to correct faults and improve operational efficiency.

Pacific Northwest National Laboratory (PNNL) has begun in this project to develop technology for systems to automatically correct soft faults associated with incorrect set points, improper values for other control parameters (e.g., control constants), oscillating valves and dampers, sensor faults, incorrect control strategies, poor use of equipment scheduling, and other problems that can be corrected by changing software code or the values of constants used for control purposes. Although physical (hard) faults and failures, such as a bent damper linkage, cannot be corrected automatically, automatic adjustment could potentially be implemented to compensate for hard faults. By adding self-compensation for hard faults, the energy use of HVAC systems could be minimized in the presence of physical faults until repairs can be performed to correct them, optimizing operation to the best performance possible in the presence of such faults. Hard fault compensation, however, was not the focus on this project, only soft fault correction.

The PNNL team has developed algorithms for automatically correcting selected soft faults in airhandler dampers and sensors (Fernandez et al. 2009). These algorithms have been coded in software and tested on an air-handling unit under laboratory conditions in the fall of 2009. These algorithms automatically, in real time, correct and optimally compensate for faults occurring in the air handling, and could be applied to built-up air handlers, packaged airhandling units, and packaged HVAC units (air conditioners and heat pumps), addressing a number of commonly occurring faults such as improper economizer operation. Air-handling represents the first, yet very important, application of self-correcting controls to HVAC because of the high prevalence of economizer faults and the potential energy/cost impacts of improperly controlled economizers when they are not used and when they are operated incorrectly. Field demonstration is the next logical step in advancing the technology developed in this project, but the technical team recommends further laboratory testing before proceeding to field tests (the reasons for which will be discussed later in this report).

The objective of the project was to develop and test (in the laboratory) algorithms that implement self-correction capabilities for temperature, humidity and pressure sensors, economizer dampers, and damper actuators in HVAC systems. Satisfaction of this objective will lead to 1) algorithms ready for implementation in controllers for field demonstration and commercial application and 2) underlying methods that may be transferable to creating selfcorrecting capabilities for other HVAC system components. Full-scale commercial deployment of this technology will capture significant energy savings by automatically eliminating many of the faults that degrade the efficiency of HVAC systems, thus maintaining energy efficiency well above the efficiency at which these systems routinely operate. Furthermore, to the extent that 
HVAC electricity use and system peaking are coincident (e.g., in the summer), peak demand will also be reduced by deployment of this technology.

The objectives of the project were to:

1. develop algorithms that implement self-correction capabilities for temperature, humidity and pressure sensors, economizer dampers, and damper actuators in HVAC systems, and

2. test the algorithms developed on actual equipment in a laboratory.

Satisfaction of these objectives was intended to lead to:

1. algorithms ready for field demonstration and commercial application,

2. underlying methods that may be transferable to creating self-correcting capabilities for other HVAC system components.

Furthermore, full-scale commercial deployment of the technology will capture significant energy savings by automatically eliminating many of the faults that degrade the efficiency of HVAC systems, thus maintaining energy efficiency well above the efficiency at which these systems routinely operate. Furthermore, to the extent that HVAC electricity use and system peaking are coincident (e.g., in the summer), peak demand will also be reduced by deployment of this technology.

Overall, the objectives of the project were met, with some qualifications. Algorithms for selfcorrection of temperature and humidity sensors, economizer dampers, and damper actuator control for air handlers were developed. Because development and testing of algorithms for the air-handler mixing box was sufficiently challenging by itself, the project was not able to address pressure sensors (e.g., that would be used to measure the static pressure at the air-handler discharge).

The algorithms were tested in the PNNL building diagnostics laboratory. The laboratory tests revealed performance limitations of the algorithms, primarily associated with initial fault detection. Both the sensor tolerances specified and the outdoor conditions affect the ability to detect faults passively in the first step of the self-correction process. Although the tests performed reveal and illustrate these issues, further laboratory testing is necessary to fully characterize these limitations for each fault (and corresponding algorithm). Such limitations may, however, detract little from the value of these algorithms in practice because they do not need to detect a fault under all conditions just because it exists. This is frequently an issue with passive observational fault detection; conditions must be appropriate to reveal the fault. For example, if a fault related to air-side economizing exists, it generally will not be revealed until conditions appropriate for economizing occur. Although this is a simplistic example, it illustrates the nature of the limitations. They will be discussed more completely later in this report. 


\subsection{Prior Developments}

Although automated self-correction of faults is a new concept in the HVAC field, it has been under development in the aircraft field for nearly 30 years (Tomayko 2003, Steinberg 2005). Moreover, PNNL completed an early exploratory study of a small number of fault correction procedures for example devices and automated one example for a computer-based simulated economizer system prior to this project. The results of that work were not, however, tested on actual equipment. The present study built on that earlier work, extending it considerably by developing more complete algorithms, expanding work to additional HVAC components, and performing laboratory tests on actual equipment. A PNNL laboratory specifically developed for physically testing self-correcting HVAC controls and fault detection and diagnostics for airhandler and terminal box faults was used for testing.

\subsubsection{Other fields}

Most research and development in self-correcting controls (usually referred to in the aircraft field as fault-tolerant control systems or FTCS) have been done in the field of aircraft flight control with much less work completed in the areas of naval/marine vessels, space systems, power plants, process control, manufacturing, (land) vehicles, and other application areas (with the second most published work being for naval applications). Work in self-repairing flight control began in earnest in the late 1970s and early 1980 s primarily to improve the ability of aircraft to respond to physical faults or damage to physical flight control surfaces (wings, elevators, ailerons, etc.) and actuators controlling those surfaces to enable the aircraft to safely land while subject to these faults and failures (Tomayko 2003, Steinberg 2005). The general approach has been to enable the aircraft to continue to operate usually for a limited time until it can land, albeit with degraded performance, despite the presence of faults. Work in this field has focused primarily on development and testing of methods tied directly to feedback control loops rather than supervisory level control decisions. Furthermore, solutions have been developed primarily with an eye towards speed of response, the need to ensure correct fault detection and isolation, and handling of actuator saturation, among other problems.

In recent years (mid-1990s and later), much of the research in this field has transitioned to use of intelligent flight control and techniques from the field of artificial intelligence such as artificial neural networks and genetic algorithms. Actual flight and simulator tests have shown the techniques to be useful and successful in overcoming limited sets of faults. By the late 1990s, techniques began to see limited application in aircraft for a small number of faults as a means to improve aircraft safety. Still, practical considerations, such as how to certify automaticallyreconfigurable flight controls, remain obstacles to widespread application to a broad range of potential faults on aircraft.

\subsubsection{HVAC}

Little research and development has been performed on self-correcting or fault-tolerant controls for buildings and HVAC systems. As part of an effort to develop a supervisory control system that adapts to degradation faults to minimize energy consumption and degradation of occupant comfort, Xiong-Fu and Dexter $(1999,2001)$ from Cambridge University used fuzzy models and optimization to determine the most appropriate set points to meet their objectives. Computer simulation was used for development and evaluation of the control scheme. 
A team from Portugal and the UK (Silva et al. 2006) used the multiple-model approach, one of the mathematical methods examined extensively in the FTCS literature to improve the control of an HVAC system terminal unit in the presence of faults. The responses to two faults were tested, both associated with partial restriction of fan blade movement. The response in the presence of faults was better than that of the standard PID (proportional integral derivative) controller and showed little degradation of performance; however, the response was slow compared to the PID controller and recuperation from the fault was initially slow. The results were, however, encouraging.

Four papers on fault-tolerant control have been published by university teams in China (Wang and Chen 2002, Xiaoli et al. 2005, Jin and Du 2006, Du and Jin 2007). Wang and Chen (2002) examined a supervisory control scheme that adapts to flow sensor measurement faults. Artificial neural networks (ANNs) were trained on data for a range of normal operating conditions. The models were then used to detect faults, using residuals (differences) between the measurements from sensors and the values indicated by the ANNs under similar conditions without the measurement faults present. The values from the ANNs were then used in place of the faulty measurements in the feedback control loop to regain control of the flow rate in the presence of the sensor fault. Tests were performed using dynamic simulation models.

Xiaoli et al. (2005) used the statistical method of principle components analysis (PCA) to model monitored HVAC systems using data from normal operating conditions, to detect faulty or missing data in a data series collected over time, and to replace faulty or missing data. By replacing the faulty or missing data in the data stream to a controller, the approach enables the controller to operate effectively in the presence of these data stream problems.

The team of Jin and Du $(2006,2007)$ used PCA, joint angle method, and fault reconstruction schemes to maintain control of outdoor-air ventilation and air-handler discharge-air temperature in variable-air-volume (VAV) systems in the presence of sensor bias faults. System-level models were used to initially detect faults. The faults were verified and isolated using two locallevel models and joint angle plots. A fault reconstruction scheme was then used to estimate the magnitude of the bias faults, and corrections were then applied for the biases to regain proper control. The method has been tested using simulation.

In Katipamula and Brambley (2007) and Katipamula et al. (2003b and c), two of the authors of this report developed rules based on physical reasoning for fault detection, isolation and characterization for selected faults in temperature sensors, valves and dampers. By using these rules in conjunction with proactive testing, which would be implemented for short periods of time through the control system, the authors are able to isolate and characterize faults adequately to implement simple mathematical corrective schemes that showed promise for implementation as embedded code in control systems. One of the rule sets was implemented in a simple interactive computer-based example. No physical testing was completed as part of this initial examination of self-correcting controls for HVAC components and systems.

The authors believe that approaches based on rules derived from engineering knowledge are likely to represent the best approach for practical implementation of self-correcting controls for HVAC systems in the near- and mid-term. The present project has begun to validate this 
hypothesis by further developing and laboratory testing algorithms for a broader set of HVAC components and fault conditions.

\subsection{Overview of the Rest of the Report}

The remainder of this report presents a summary of the algorithms developed in Section 2, a description of the test apparatus in Section 3, identification of the laboratory tests performed in Section 4, the test results in Section 5, the conclusions in Section 6, and recommendations for follow-on work in Section 7. 


\section{Algorithms Developed}

The self-correction algorithms developed in this project are described in detail in the companion document Self-Correcting HVAC Controls: Algorithms for Sensors and Dampers in Air-Handling Units (Fernandez et al. 2009). The algorithms address faults for temperature sensors, humidity sensors, and dampers in air handling units, including their use for economizing. The algorithms are presented as a highly integrated set of flow charts and include processes for:

- fault detection

- fault isolation

- fault characterization, and

- fault correction.

All four processes are required to perform fault correction. In the first process, fault detection, the occurrence of a fault in the monitored system is detected. The specific fault may not be identified but the presence of some fault is detected via changes in the behavior of the system compared to normal operation, indicating that a fault of some kind is present. Fault detection is initially performed using passive observation.

The second process, fault isolation (sometimes called fault diagnosis), identifies (i.e., isolates) the specific fault that has occurred. This is accomplished using proactive tests, during which automatic control is suspended and the component or system is forced into limiting conditions (e.g., a fully open damper position).

The fault then must be characterized before it can be corrected. This may include determining that magnitude of the fault, its sign, whether it is constant, growing or decreasing with time, the rate of growth of the fault severity, whether the fault oscillates or is intermittent, and other characteristics necessary to sufficiently characterized the fault behavior that a compensating function can be developed and applied for correction. Fault characterization is performed using additional proactive tests and sometimes collection of data for many sampling periods in order to capture temporal variation of the fault, if present.

The final process is development of the compensating function (e.g., for a biased sensor, the simple subtraction of the bias [of correct magnitude and sign] from the sensor signal or indicated measured quantity in engineering units). These processes are sufficiently complex and intertwined that clear separation of them into separate flow charts is not entirely possible; therefore, some flow charts contribute to more than one of these processes and address faults with more than one type of physical component (e.g., temperature sensor and damper faults), or involve both passive fault detection and proactive fault detection/isolation.

The algorithms developed detect and correct the soft faults and detect and report the hard faults listed below:

\section{$\underline{\text { Temperature Sensor Faults }}$}


Biased mixed-air (MA) sensor, soft

Biased outdoor-air (RA) sensor, soft

Biased return-air (RA) sensor, soft

Erratic mixed-air sensor, hard

Erratic outdoor-air sensor, hard

Erratic return-air sensor, hard

\section{Damper Faults}

Outdoor-air damper minimum occupied position is too open, but damper is fully modulating, soft Dampers hunt, soft

Damper stuck fully open, completely closed or between fully open and completely closed, hard Outdoor-air damper does not modulate to fully open (100\% OA), hard

Outdoor-air damper does not modulate to completely closed (100\% RA), hard

Relative Humidity $(\mathrm{RH})$ Sensor Faults

Biased mixed-air RH sensor, soft

Biased outdoor-air RH sensor, soft

Biased return-air $\mathrm{RH}$ sensor, soft

Erratic mixed-air RH sensor, hard

Erratic outdoor-air RH sensor, hard

Erratic return-air $\mathrm{RH}$ sensor, hard

System Level Fault

Automatic control overridden too long, soft 


\section{Test Apparatus}

The self-correcting control (SCC) algorithms were tested on an actual physical system in the PNNL Building Diagnostics Laboratory. This section describes the apparatus used for these tests.

\subsection{Physical Description}

The apparatus consists of three interconnected systems, a commercial air handler, an aircooled chiller, which provides chilled water to the cooling coil of the air handler, and a control system. A diagram of the test apparatus is shown in Figure 1.

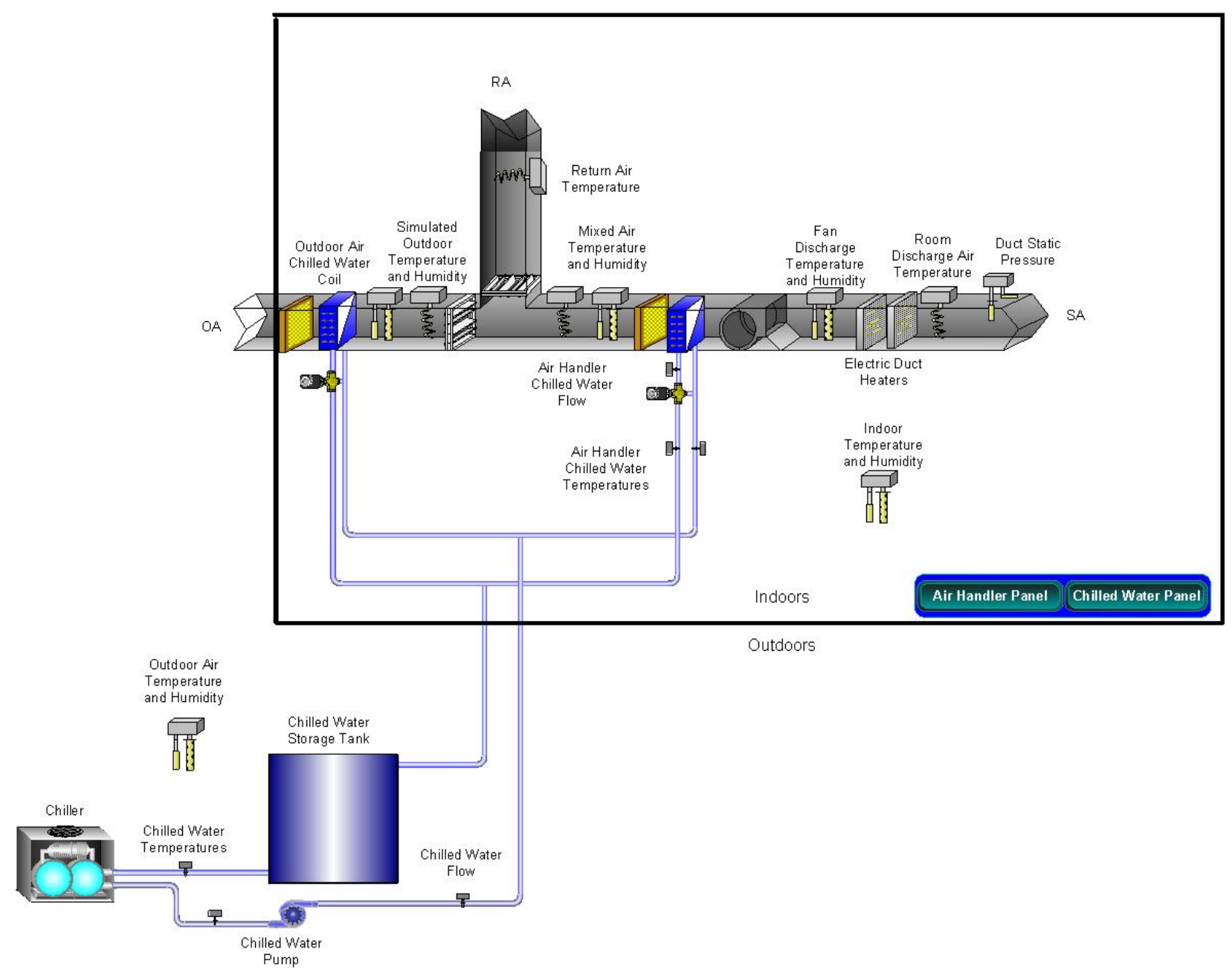

Figure 1: Diagram of test apparatus. Distances between components are not shown to scale.

In the air handler, outdoor air brought in through the outdoor-air duct is mixed with air returning from the conditioned space through a parallel-blade return-air damper. Upon entering the duct, the outdoor air passes through a filter and an outdoor-air chilled-water coil. The OA chilledwater coil, which is not present in actual air-handling units used in buildings, provides the capability to control the temperature of the "outdoor-air" that enters the air-handler mixing box. During hot outdoor conditions, this coil provides the capability to pre-cool the raw outdoor air to 
a desired temperature before it is mixed with return air. As a result, for purposes of testing, the temperature and humidity of this pre-conditioned outdoor air represent the entering outdoor-air conditions for the air-handler. Although not implemented prior to performing tests for this project, the ability to also pre-condition the outdoor air to a desired temperature by heating will be added in the future, enabling tests corresponding to spring, fall and even summer conditions to be run during cold winter days. Because the capability to pre-heat the raw outdoor air was not installed prior to tests for this project, the tests were subject to the naturally occurring outdoor-air conditions, limiting the range of conditions during testing somewhat.

Downstream of the OA chilled-water coil is a Johnson Controls HE-6703 Relative Humidity sensor ${ }^{1}$, with an accuracy of $+/-3 \% \mathrm{RH}$, and a pencil-probe temperature sensor with an accuracy of $+/-2^{\circ} \mathrm{F}$. These two sensors measure the actual temperature and relative humidity of the pre-conditioned outdoor-air stream. An opposing-blade outdoor-air damper is located downstream of these two sensors. This damper and the mixed-air damper control the relative proportion of outdoor air and return air entering the mixing box.

The temperature of the return-air stream is measured using a sensor identical to that used for the outdoor-air stream. A Johnson Controls HE-67N2-0N00P sensor ${ }^{2}$ with an accuracy of $+/-$ $2 \% \mathrm{RH}$, mounted on a wall of the room near the air-handler is used to measure the return-air relative humidity.

Temperature and relative humidity sensors are located 2 feet downstream of the return-air damper in the mixing box. The temperature sensor is an averaging sensor with an accuracy of $+/-0.34^{\circ} \mathrm{F}$. The averaging sensor combines the measurements of several thermocouples that are located a cable that is mounted to snake back and forth across the mixing box. This helps account for spatial temperature variations that may exist in the mixed-air stream.

The cooling coil of the air handling unit is located downstream of the mixing box. This coil is used to cool the mixed-air stream to the desired discharge-air temperature for air-conditioning the spaces served by the air-handler. The supply fan is located downstream of the cooling coil and is controlled by a variable frequency drive (VFD). Sensors for measuring the temperature and relative humidity of the discharge air are located downstream of the supply fan.

For purposes of imposing a cooling load on the air-handling unit greater than might naturally occur in this laboratory, three banks of electric resistance duct heaters are located further downstream. Another probe-type temperature sensor and a differential pressure sensor for are located downstream of the duct heaters. The air discharged from the unit is distributed to four variable-air-volume (VAV) boxes, two located in the same room as the air handler and two in an adjacent room. The VAV boxes were not used in the tests for this project.

\footnotetext{
${ }^{1}$ Trade names are referenced for identification of specific components used in the research and is not an endorsement of the products of a particular manufacturer.

${ }^{2}$ Trade names are referenced for identification of specific components used in the research and is not an endorsement of the products of a particular manufacturer.
} 
Chilled water for cooling is supplied by a 13-ton air-cooled chiller located outdoors. Cold water from the chiller is pumped to a insulated storage tank (of approximately 100 gallon volume). The chiller is oversized relative to the air handling unit. To prevent rapid cycling of the chiller, chilled water is pumped from the chiller to the storage tank. The chiller maintains the temperature in the water tank based on feedback from the control system which uses measurements from temperature sensors in the chilled-water loop. Chilled water is then drawn from the tank to supply the cooling coil and the outdoor-air pre-cooling coil, when it is used. The two coils are piped in parallel so that the flow rates through the two coils can be controlled independently.

The control system consists of a programmable logic controller (PLC), a building automation server (BAS), an OPC (Object Linking and Embedding [OLE] for Process Control) server, a human machine interface (HMI), and a database server as shown in Figure 2. The PLC collects data, including temperature and humidity sensor signals and damper position signals, and controls the damper position, chiller and supply fan. The inputs are collected from two input/output data acquisition modules. The BAS, also referred to as the network automation engine (NAE), is a web-enabled network controller that communicates using information technology (IT) and Internet languages. The BAS acts as a bridge between the PLC and user interface/database and allows a fine level of control. All high level programming is written in the BAS. Programs in the BAS can be manipulated or viewed by a user logged into the server. The BAS is connected to the OPC server, which acts as a gateway to an $\mathrm{HMI}$ and a computer server. The OPC server is a software application that acts as an application programming interface or protocol converter. It translates the data into an industry standard format. The HMI is implemented in FPMI (Factory Plant Management Interface). FPMI is a web-based front-end to the OPC server and Structured Query Language (SQL) database. Using the FPMI client interface, users can monitor live data, specify the control variables and sensor paths, and initiate tests of diagnostics and correction algorithms. The test data and control variables are stored using a database server.

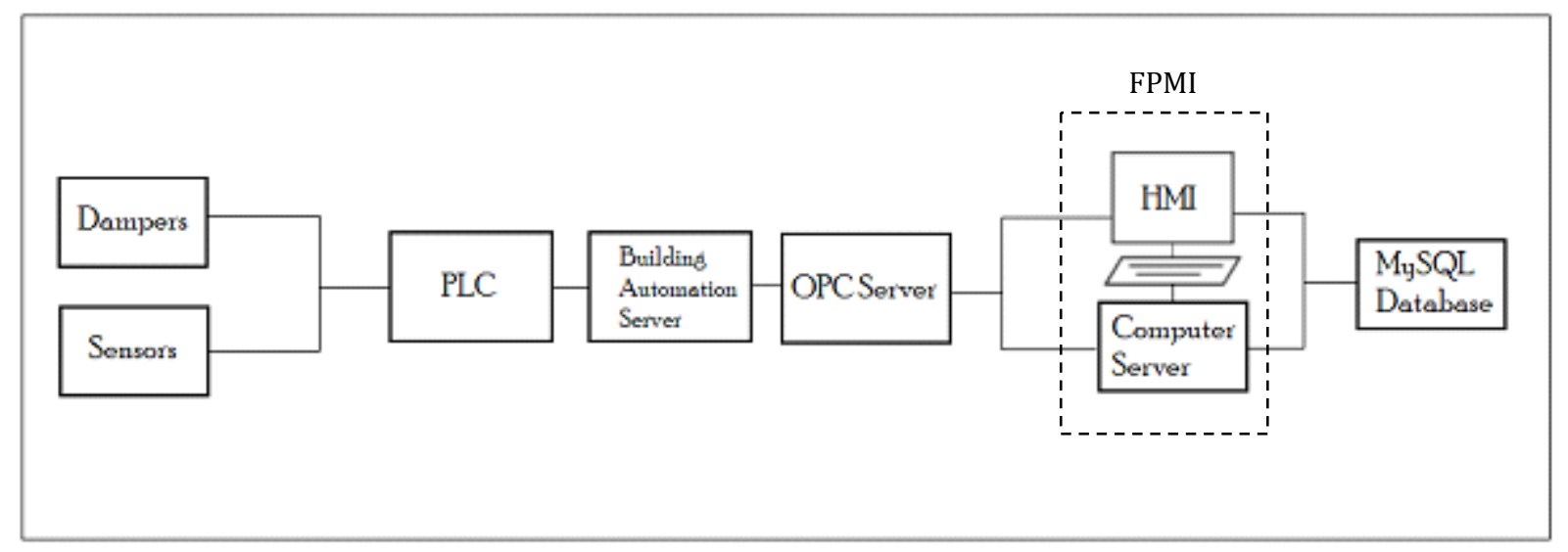

Figure 2: Control system with web-based user control interface. 


\subsection{Logical Description}

The test apparatus was maintained during testing, ensuring that all sensors were calibrated and operating properly, and both of the dampers were modulating through their full range of operation. Faults were simulated through a set of virtual sensor and control points (compare Figure 3, Figure 4 and Figure 5). For a simple single-input single output controller, the signal produced by a sensor measuring a property or characteristic of the controlled system is fed to the controller, which produces an output actuator signal, using a control algorithm. The control algorithm is a procedure that relates values of the input variable (in this case, the sensor signal) to the output (in this case, the actuator signal). The actuator responds to receiving the actuator signal by instigating an action, e.g., moving a damper or valve, changing an electrical resistance, etc.

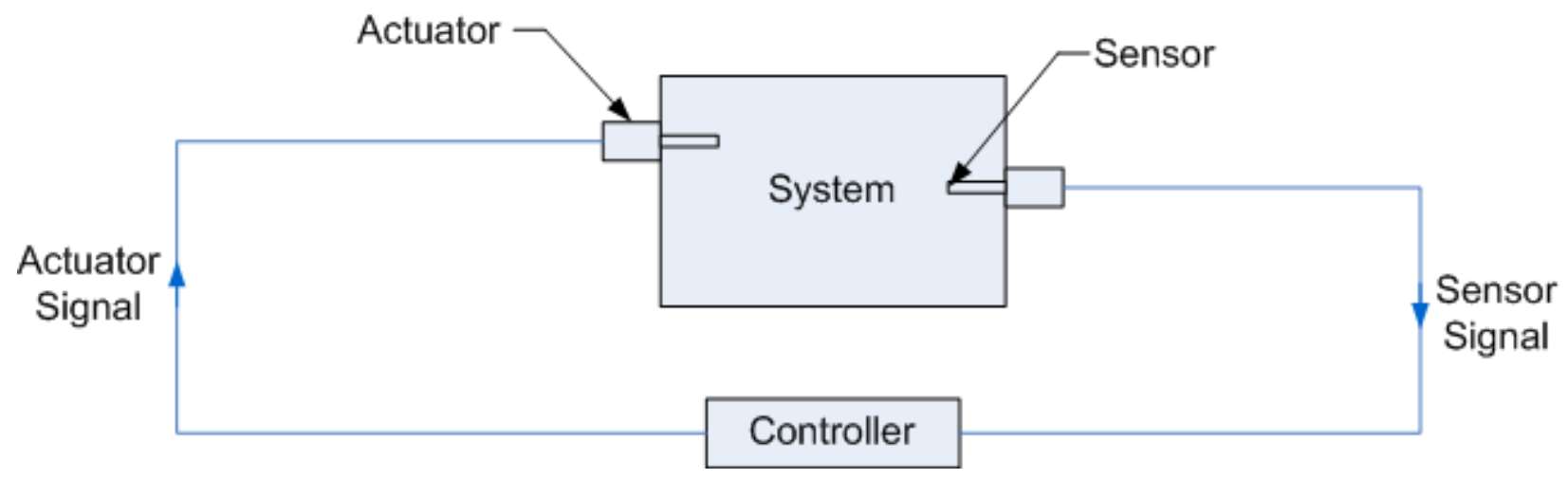

Figure 3: Schematic diagram of the relationships among a sensor, controller and actuator for ordinary control (without correction) of a system.

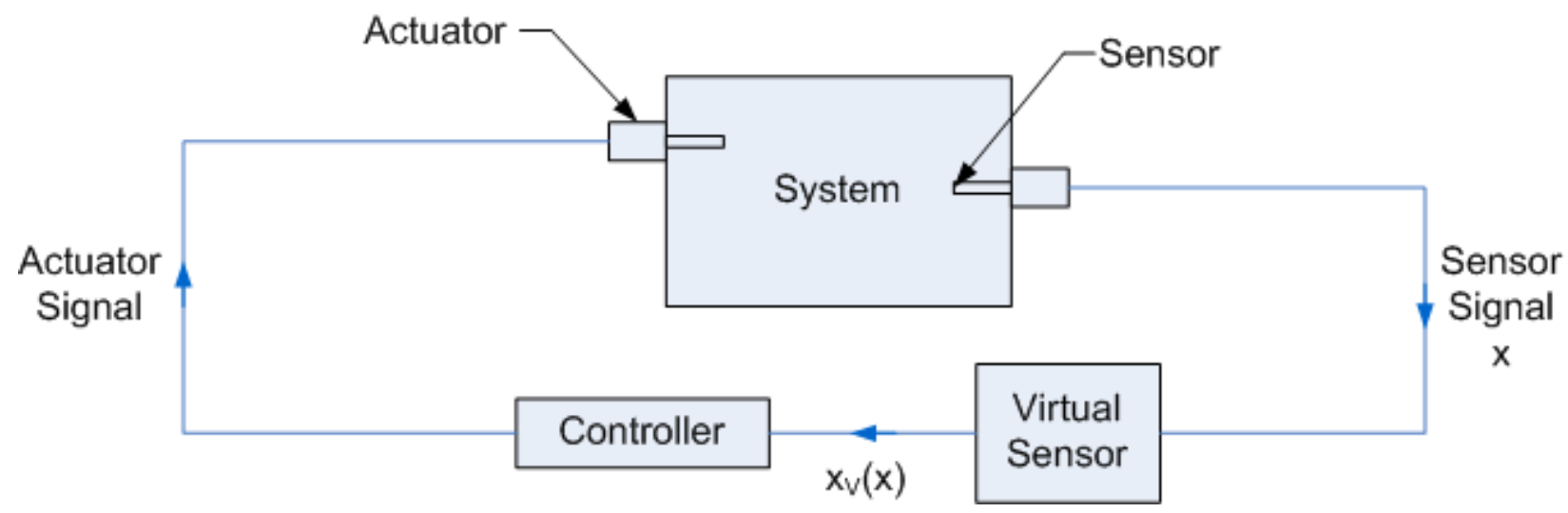

Figure 4: Schematic diagram of a controlled system with a virtual sensor point added through which corrections to a faulty sensor signal can be implemented.

In Figure 4, a virtual sensor has been added in which corrections to sensor faults can be implemented given that the proper corrective action has been identified (for simplicity the process for determination of the corrective action is not shown in this figure). The virtual sensor 


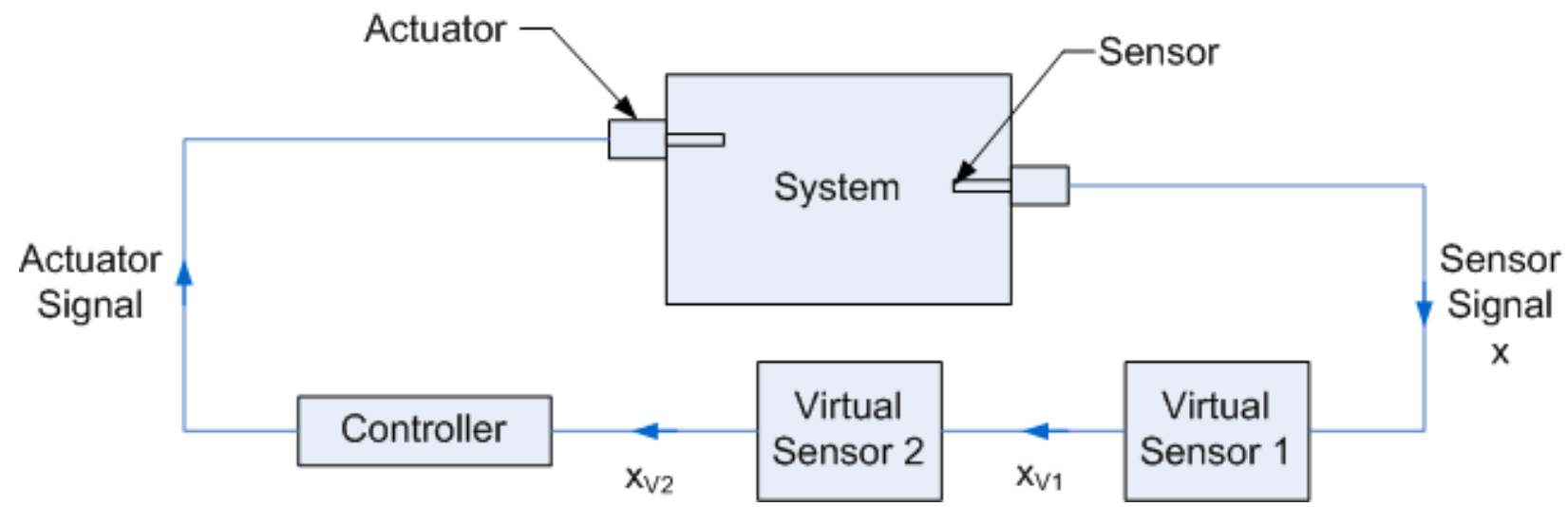

Figure 5: Diagram of system used to implement and correct faults using two virtual sensors.

uses a correction algorithm to convert a faulty sensor signal, when a fault exists, to the correct value that the sensor should have output under the conditions at the time of the measurement. This corrected virtual sensor value, $x_{v}(x)$, is a unique function of the specific fault that has occurred in the sensor and the value of the sensor output $(x)$.

Figure 5 shows the approach used in the test apparatus to implement faults using software and to correct faults. Two virtual sensors are used. Virtual Sensor 1 is used for implementing sensor faults by converting a correct sensor signal $(x)$ to a faulty sensor signal $\left(\mathrm{x}_{\mathrm{V} 1}\right)$ using a mathematical function that creates the desired sensor fault. For example, a positively biased sensor output would be created by the function $x_{V_{1}}=x+b$, where $b$ is the magnitude of the bias. This function could be used to make Virtual Sensor 1 behave like a sensor with an output that is always $10^{\circ} \mathrm{F}$ too high. If the faulty value of $\mathrm{x}_{\mathrm{V} 1}$ were input to the controller, the controller would then output an incorrect value for the actuator signal, resulting in the actuator causing the wrong action for the actual current conditions. The faults implementable with this scheme are not limited to bias faults. Any fault for which a mathematical function can be specified can be implemented in Virtual Sensor 1 to create a faulty sensor output. This includes faults that increase with time at various rates, oscillating faults, and intermittent faults.

Virtual Sensor 2 is introduced (as was the virtual sensor in Figure 4) to correct the faulty output of Virtual Sensor $1\left(\mathrm{x}_{\mathrm{v}_{1}}\right)$. Algorithms for the self correction process automatically detect that a fault has occurred, isolate it to a specific sensor, characterize it, and then implement a function that corrects the fault to produce a correct sensor value $\mathrm{x}_{\mathrm{V} 2}$.

In the actual situation (Figure 4), only one virtual sensor would be used, this to correct for faults in the actual physical sensor when then occur. In that case, when $x_{v}$ is input into the controller, the correct value of the actuator signal is produced and the actuated device responds correctly, even though the output of the physical sensor $(x)$ is faulty. Figure 6 shows the process when implemented in practice, including the components that perform fault detection, fault isolation, fault characterization, and formulation of the fault correction. These processes are executed sequentially, so faults are not corrected immediately using this approach. The time from fault detection to fault correct may take minutes or even hours, but this is acceptable for most HVAC system faults, whereas it would not be for some safety critical systems; however, this sort of 
difference (as well as others) distinguishes HVAC requirements from other application domains and the solutions that are appropriate to each.

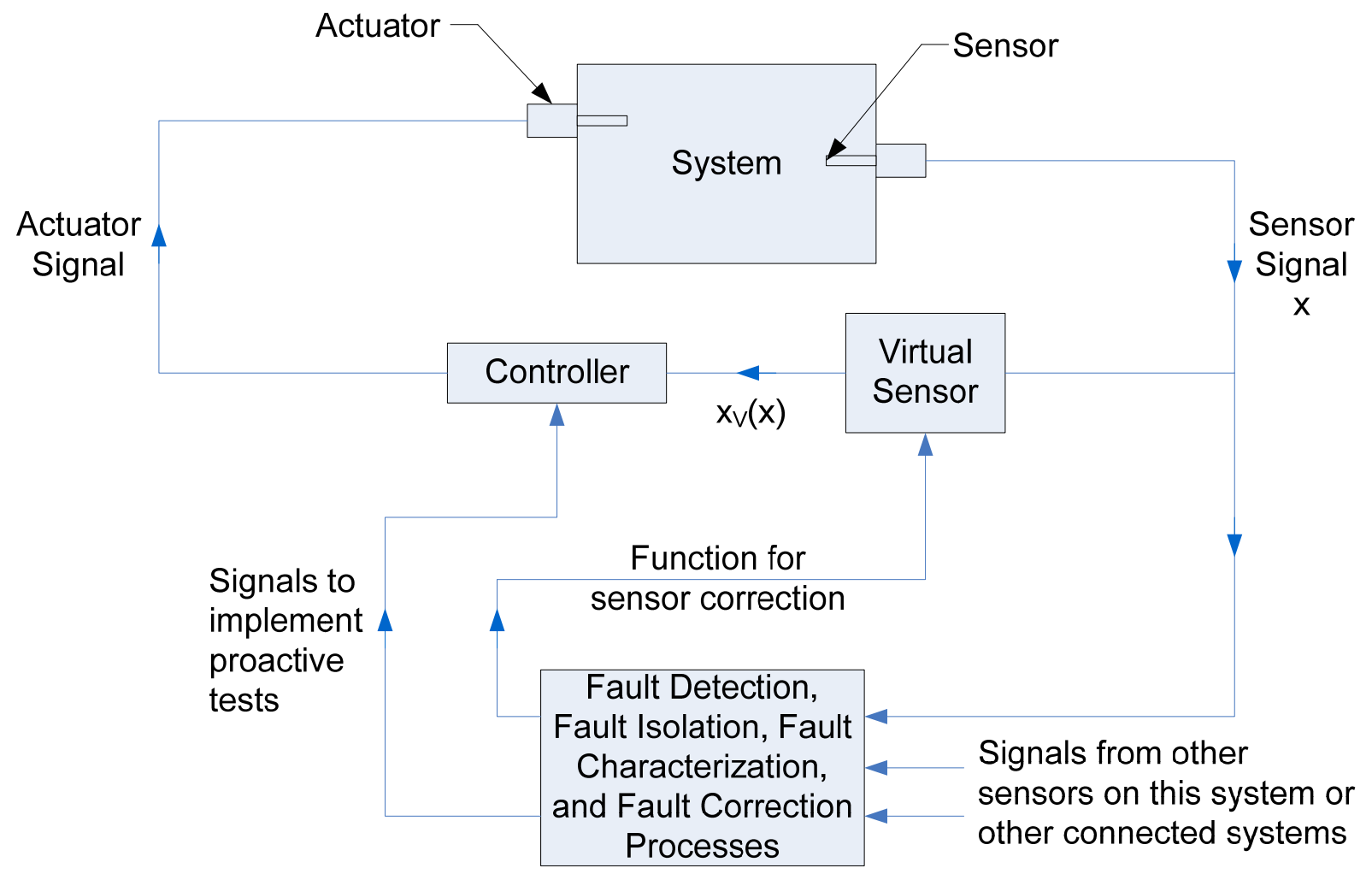

Figure 6: System schematic showing supervisory fault detection, isolation, characterization and correction processes interfacing with the virtual sensor and controller.

From the standpoint of the control system, the virtual sensor points are the measurements that are acted upon. When no fault is present the virtual sensor output is identical to the physical sensor signal (i.e., the corrective function is just an equality of input to output, e.g., $\left.x_{V}(x)=x\right)$.

In the laboratory system, a virtual point has been defined for each sensor and each control point, so tests can be performed on any variable selected.

The sensor faults tested were limited to positive and negative bias faults. For this case, two virtual points are created for instigating and correcting the sensor fault, as shown in Figure 5. For example, for a faulty outdoor-air temperature sensor, the overall relationship between the measured value produced by the faulty physical sensor ( $\left.T_{\text {OA,MEASURED }}\right)$ and the corrected virtual temperature sensor point ( $\left.T_{O A, V I R T U A L}\right)$ is given by the relation

$$
T_{\text {OA,VIRTUAL }}=T_{\text {OA,MEASURED }}+\text { bias }_{\text {OA,INSTIGATED }}-\text { bias }_{\text {OA,CORRECTED }},
$$

where biaS OA,INSTIGATED $_{\text {is }}$ the bias fault instigated and biaS OA,CORRECTED $_{\text {is }}$ ise bias correction determined by the fault correction process. For a perfect correction process, the corrected bias 
would equal the instigated bias identically. In practice, however, as the test results will show, the values of these two variables can and will differ.

Using a generalized form, any temperature or humidity sensor bias can be simulated by changing the 'instigated bias' in a virtual sensor. The bias also is not restricted to being constant. The bias (or error) can be any function ranging from a constant to a bias that varies with time (sensor drift) or as a function of temperature. It can also be an excessive noisy sensor by overlaying a noise function onto the measured sensor signal. The tests completed for the project, however, only consider the simplest case of a constant bias. This discussion though explains how both the method of correction and laboratory could be extended to more complex faults.

As a example of the testing procedure, we consider a biased outdoor-air temperature sensor. The steps involved in instigating and testing the correction algorithm are:

1) Initially, the first virtual outdoor-air temperature sensor output equals the measured outdoorair temperature because no bias fault has been instigated (i.e., bias OA,INSTIGATED $=0$ ) and no bias correction has been implemented previously for the outdoor-air temperature sensor (i.e., biaS $\left._{O A, C O R R E C T E D}=0\right)$.

2) A bias fault is instigated by changing bias $_{\text {OA,INSTIGATED }}$ to a non-zero value, starting the test. Let's say the instigated bias is $5^{\circ} \mathrm{F}$. The first Virtual OA temperature is then $5^{\circ} \mathrm{F}$ higher than the measured outdoor-air temperature (i.e., $T_{\text {OA,VIRTUAL }}=T_{\text {OA,MEASURED }}+5^{\circ} \mathrm{F}$ ).

3) The fault is detected by the software code implementing the fault detection algorithms, and , and the program would run a fault isolation (i.e., diagnostic) process to isolate the specific sensor with the fault. After isolation of the faulty sensor, a process runs to characterize the fault. In this case, it finds that the fault is a bias and determine the magnitude of the bias. Because of uncertainties in measurements and other factors, the magnitude of the fault as characterized may not exactly equal the actual fault magnitude of $5^{\circ} \mathrm{F}$. Say the fault correction algorithm determines that the $\mathrm{OA}$ sensor bias is $+4.5^{\circ} \mathrm{F}$.

4) The physical system continues to run, but now using the value output by the second virtual sensor, which is given by $T_{\text {OA,VIRTUAL }}=T_{\text {OA,MEASURED }}+5^{\circ} \mathrm{F}-4.5^{\circ} \mathrm{F}$. The corrected virtual sensor output is $0.5^{\circ} \mathrm{F}$ higher than the actual temperature but an order of magnitude closer to it than the faulty temperature sensor reading.

Virtual sensors points were created for the outdoor-, return- and mixed-air temperature sensors and relative humidity sensors, as well as for the calculated outdoor-air fraction (OAF). The $O A F_{\text {virtual }}$ is given by the relation

$$
O A F_{\text {virtual }}=\frac{T_{M A, V I R T U A L-} T_{R A, V I R T U A L}}{T_{\text {OA,VIRTUAL }}-T_{R A, V I R T U A L}} .
$$




\subsection{Using the Test Apparatus to perform SCC tests}

The test apparatus is generally run continuously with the outdoor-air damper at the minimum occupied position. This is the outdoor-air damper position that provides the minimum amount of outdoor air required to meet the ventilation needs of building occupants. Air handlers generally operate at this damper position while buildings are occupied except when economizing. The minimum occupied position does not correspond to the outdoor damper being fully closed, because outdoor-air ventilation must be provided for building occupants; however, when a building is not occupied, the outdoor-air damper should be fully closed to minimize energy consumption for space conditioning.

Continuous operation of the laboratory air handler entails running the supply fan continuously while sending the damper system a voltage signal that corresponds to the minimum occupied position. The damper control signal ranges from 0 volts for a completely closed outdoor-air damper (and fully open return-air damper) and 10 volts for the outdoor-air damper fully open (and return-air damper completely closed). Within the SCC software code, the damper positioning signal is normalized to a range of 0 to 100 , corresponding to the outdoor air damper positioned from completely closed (0-volt signal) to fully open (10-volt signal), to provide an more intuitive indicator of the outdoor-air damper position ( $0 \%$ to $100 \%$ open).

For commercial buildings, a key step in commissioning an air-handling unit is to determine the minimum occupied damper position signal. Frequently, the assumption is made during installation and setup that the outdoor-air damper position is directly proportional to the damper positioning signal so, for example, if an outdoor-air ventilation rate of $20 \%$ of the maximum ventilation rate with the outdoor-air damper fully open is desired, then the damper signal is set to $20 \%$ of maximum (or 2 volts for a signal range of 0 to 10 volts). Actual damper response, however, if non-linear and this approach leads to incorrect damper positioning for the minimum occupied ventilation rate. As a result, detection and correction of this type of damper positioning error is very important.

To understand the actual behavior of the damper system in the laboratory air handler, a response curve was empirically developed for the system. This curve can be used to determine the signal required to provide the desired minimum occupied position. Because airflow sensors are generally not installed in air-handling units because they are somewhat complex and relatively expensive, we use the outdoor-air fraction (OAF) as the next best indicator of the amount of outdoor air entering the system. The OAF can be readily calculated from the temperatures of the outdoor-, return- and mixed-air, using the relation

$$
O A F=\frac{T_{M A}-T_{R A}}{T_{O A}-T_{R A}}
$$

To determine the relationship between damper signal and OAF for this test apparatus, measured date were collected while modulating the normalized damper signal from 0 to 100 
and then back from 100 to 0 in steps of 10 . The resulting relationship between the OAF and damper position signal is shown in Figure 7.

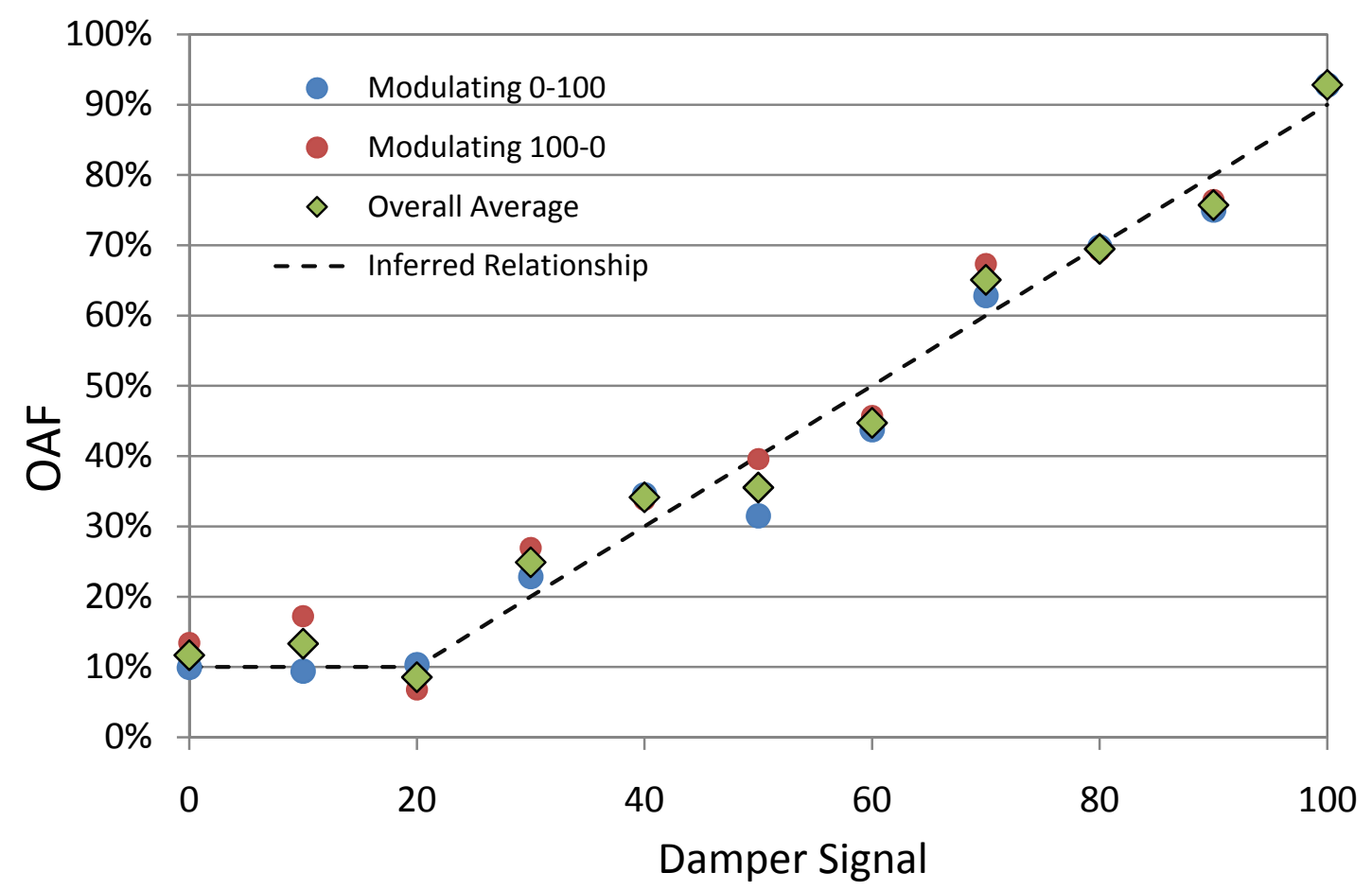

Figure 7: Relationship between damper signal and OAF.

Two important characteristics are evident for this particular system. First, the outdoor-air and return-air dampers do not physically respond to changes in the damper signal in the range of 0 to 20. The outdoor-air damper remains in its fully closed position for this range of signals, and the return-air damper remains in its fully open position. Second, when one damper is fully open, there is about $10 \%$ leakage through the other damper. This has some important consequences for the fault detection, diagnosis, and correction processes, which are discussed in Section 5 of this report. Between a damper signal of 20 and 100, the OAF appears approximately increase linearly from $10 \%$ to a maximum of $90 \%$. In general, for testing purposes, the damper signal at minimum occupied position was set to 35 , corresponding to an OAF of about $30 \%$.

The SCC code is configured for the passive diagnostics algorithms run every 5 minutes, whenever a test is initiated, using all of the virtual sensor points to determine if a fault is present. At the beginning of each test, the "corrected bias" component of the virtual sensor is set to zero, and "instigated bias" is set to the value selected for the specific test. To simplify testing, the system was always run in minimum occupied position as a default. This is different from the operation during economizing for which the dampers would modulate to achieve the levels of outdoor air necessary to provide the desired level of free cooling (when outdoor conditions are appropriate for economizing). During the tests, the return-air temperature was set to $70{ }^{\circ} \mathrm{F}$ by maintaining the room at this temperature. The duct heaters in the system (see Figure 1) cycled on and off automatically to maintain the room temperature at approximately $70^{\circ} \mathrm{F}$. At times, 
the room-air temperature oscillated about this set point. All tests were performed in late autumn, when the outdoor-air temperature was less than the return-air temperature. Because no pre-heater was yet installed in the outdoor-air duct, the outdoor-air temperature was left uncontrolled for the duration of testing. 


\section{Testing}

Being the first tests of self-correction for air handling, testing for this project focused on investigating automatic correction of soft faults in the air handler. The goal of the testing was two-fold. The first goal is to determine how effectively the proposed rule-based algorithms detect, diagnose, and correct faults under actual driving conditions. A failure of the algorithms to do so could be caused by a previously unforeseen problem in the formulation of the algorithms or natural limitations of the algorithms in detecting faults under certain driving conditions. The second goal is to determine the sensitivity of the fault detection and correction processes to the specified tolerances for measured variables, which have an influence on the ability to detect when a fault condition exists (see section 2.5 of Fernandez et al. (2009) for a description of the role of tolerances in fault detection, diagnosis and correction). When the tolerances are decreased, the minimum fault severity at which detection is possible decreases for a specific fault, but the likelihood that the algorithms will reach an incorrect conclusion also increases. Two types of incorrect conclusions can occur, detection of a fault when none exists (a false positive) and the wrong component is identified as faulty and automatically "corrected." A third type of error can also occur, not detecting a fault when one is present (a false negative), but this generally has much less significant consequences, than the other two types of faults, and occurs whenever conditions (e.g., the fault severity) are below the limits of detection of the algorithms.

The tests performed included detection, diagnosis, and correction of two basic types of airhandler sensor faults, biases in temperature sensors and relative-humidity sensors plus one type of damper fault, an incorrectly set damper signal for the minimum occupied position. A list of all tests performed is shown in Table 1. For each test, the table provides the type of fault, the specific component that the fault is applied to, the severity of the fault, and the tolerances set for temperature and relative humidity measurements. The tolerances in the table are for individual sensors, and are applied identically for all sensors of the same kind.

Table 1: Test matrix.

\begin{tabular}{|l|l|l|l|l|}
\hline Test \# & Fault Type & Component & Severity & $\begin{array}{l}\text { Temperature/RH } \\
\text { Tolerances }\end{array}$ \\
\hline $\mathrm{T}-1$ & $\begin{array}{l}\text { Temperature } \\
\text { Sensor }\end{array}$ & Return-Air Sensor & $-3^{\circ} \mathrm{F}$ & $2^{\circ} \mathrm{F} / 3 \%$ \\
\hline T-2 & $\begin{array}{l}\text { Temperature } \\
\text { Sensor }\end{array}$ & Return-Air Sensor & $-3^{\circ} \mathrm{F}$ & $1^{\circ} \mathrm{F} / 3 \%$ \\
\hline T-3 & $\begin{array}{l}\text { Temperature } \\
\text { Sensor }\end{array}$ & Return-Air Sensor & $+3^{\circ} \mathrm{F}$ & $2^{\circ} \mathrm{F} / 3 \%$ \\
\hline T-4 & $\begin{array}{l}\text { Temperature } \\
\text { Sensor }\end{array}$ & Return-Air Sensor & $+5^{\circ} \mathrm{F}$ & $2^{\circ} \mathrm{F} / 3 \%$ \\
\hline
\end{tabular}




\begin{tabular}{|c|c|c|c|c|}
\hline $\mathrm{T}-5$ & $\begin{array}{l}\text { Temperature } \\
\text { Sensor }\end{array}$ & Return-Air Sensor & $+5^{\circ} \mathrm{F}$ & $2^{\circ} \mathrm{F} / 3 \%$ \\
\hline T-6 & $\begin{array}{l}\text { Temperature } \\
\text { Sensor }\end{array}$ & Return-Air Sensor & $-8^{\circ} \mathrm{F}$ & $2^{\circ} \mathrm{F} / 3 \%$ \\
\hline$T-7$ & $\begin{array}{l}\text { Temperature } \\
\text { Sensor }\end{array}$ & Return-Air Sensor & $+8^{\circ} \mathrm{F}$ & $2^{\circ} \mathrm{F} / 3 \%$ \\
\hline $\mathrm{T}-8$ & $\begin{array}{l}\text { Temperature } \\
\text { Sensor }\end{array}$ & Outdoor-Air Sensor & $+8^{\circ} \mathrm{F}$ & $2^{\circ} \mathrm{F} / 3 \%$ \\
\hline T-9 & $\begin{array}{l}\text { Temperature } \\
\text { Sensor }\end{array}$ & Outdoor-Air Sensor & $-8^{\circ} \mathrm{F}$ & $2^{\circ} \mathrm{F} / 3 \%$ \\
\hline$T-10$ & $\begin{array}{l}\text { Temperature } \\
\text { Sensor }\end{array}$ & Mixed-Air Sensor & $+8^{\circ} \mathrm{F}$ & $2^{\circ} \mathrm{F} / 3 \%$ \\
\hline $\mathrm{RH}-1$ & RH Sensor & Mixed-Air Sensor & $-10 \%$ & $2^{\circ} \mathrm{F} / 3 \%$ \\
\hline $\mathrm{RH}-2$ & RH Sensor & Mixed-Air Sensor & $-20 \%$ & $2^{\circ} \mathrm{F} / 3 \%$ \\
\hline $\mathrm{RH}-3$ & RH Sensor & Mixed-Air Sensor & $-30 \%$ & $2^{\circ} \mathrm{F} / 3 \%$ \\
\hline MOP-1 & $\begin{array}{l}\text { Damper Signal at } \\
\text { Minimum Occupied } \\
\text { Position Incorrectly } \\
\text { Set }\end{array}$ & $N / A$ & $\begin{array}{l}\text { Damper Signal } \\
\text { at M.O.P. }{ }^{3}=50, \\
\text { Expected OAF = } \\
30 \%\end{array}$ & $2^{\circ} \mathrm{F} / 3 \%$ \\
\hline MOP-2 & $\begin{array}{l}\text { Damper Signal at } \\
\text { Minimum Occupied } \\
\text { Position Incorrectly } \\
\text { Set }\end{array}$ & N/A & $\begin{array}{l}\text { Damper Signal } \\
\text { at M.O.P. }=20 \text {, } \\
\text { Expected OAF = } \\
30 \%\end{array}$ & $2^{\circ} \mathrm{F} / 3 \%$ \\
\hline MOP-3 & $\begin{array}{l}\text { Damper Signal at } \\
\text { Minimum Occupied } \\
\text { Position Incorrectly } \\
\text { Set }\end{array}$ & N/A & $\begin{array}{l}\text { Damper Signal } \\
\text { at M.O.P. }=20, \\
\text { Expected OAF = } \\
30 \%\end{array}$ & $3^{\circ} \mathrm{F} / 3 \%$ \\
\hline MOP-4 & $\begin{array}{l}\text { Damper Signal at } \\
\text { Minimum Occupied } \\
\text { Position Incorrectly } \\
\text { Set }\end{array}$ & N/A & $\begin{array}{l}\text { Damper Signal } \\
\text { at } M . O . P .=65 \text {, } \\
\text { Expected OAF = } \\
30 \%\end{array}$ & $3^{\circ} \mathrm{F} / 3 \%$ \\
\hline
\end{tabular}

\footnotetext{
${ }^{3}$ M.O.P. $=$ minimum occupied position.
} 


\section{Test Results}

In this section, results from the tests described in Section 4 are presented, organized by fault type.

\subsection{Temperature Sensor Bias Tests}

The results from test of the algorithms to detect and correct bias faults in temperature sensors are presented in Table 2. The instigated fault and the driving conditions (outdoor-air and returnair temperatures) during the test are shown on the left side of the table. On the right side of the table are the results of each stage of the SCC process. In the passive detection column, the type of passive test that was responsible for the detection of the fault (when applicable) is displayed. Two passive tests are used to detect a temperature sensor fault (see Fernandez et al. 2009). The "Temperature Sensor Passive Diagnostic Test" (Fernandez et al. 2009, Figure 5; see Appendix), abbreviated in the "Passive Detection" column of Table 2 as "Temp," checks whether the mixed-air temperature is within the bounds of the return-air and the outdoor-air temperatures, because a failure to be within these bounds is physically impossible and indicates a sensor error. The second test, the "Minimum Occupied Position Passive Test" (Fernandez et al. 2009, Figure 6; see Appendix), checks whether the observed OAF at the minimum occupied position is close enough to the expected OAF at the minimum occupied position, based on response curve for the outdoor-air damper (like that shown in Figure 7) and accounting for the temperature sensor tolerances. This fault is abbreviated in the "Passive Detection" column of Table 2 as M.O.P.

Table 2: Results of tests for biased temperature sensors.

\begin{tabular}{|c|c|c|c|c|c|c|}
\hline Test \# & $\begin{array}{l}\text { Sensor and } \\
\text { Severity }\end{array}$ & $\begin{array}{l}\text { Outdoor Air } \\
\text { Temperature }\end{array}$ & $\begin{array}{c}\text { Return Air } \\
\text { Temperature }\end{array}$ & $\begin{array}{l}\text { Passive } \\
\text { Detction }\end{array}$ & $\begin{array}{c}\text { Proactive } \\
\text { Diagnostics }\end{array}$ & $\begin{array}{c}\text { Fault } \\
\text { Correction }\end{array}$ \\
\hline Baseline & None & $39-47^{\circ} \mathrm{F}$ & $60-79^{\circ} \mathrm{F}$ & None & None & None \\
\hline T-1 & $\mathrm{T}_{\mathrm{RA},}-3^{\circ} \mathrm{F}$ & $35-45^{\circ} \mathrm{F}$ & $70-75^{\circ} \mathrm{F}$ & 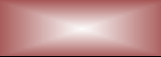 & & \\
\hline $\mathrm{T}-2 \mathrm{a}$ & $\mathrm{T}_{\mathrm{RA},}-3^{\circ} \mathrm{F}$ & $53-58^{\circ} \mathrm{F}$ & $68-75^{\circ} \mathrm{F}$ & M.O.P & $\mathrm{T}_{\mathrm{MA}}$ & $+2.3^{\circ} \mathrm{F}, \mathrm{MA}$ \\
\hline$T-2 b$ & $\mathrm{~T}_{\mathrm{RA}},-3^{\circ} \mathrm{F}$ & $53-57^{\circ} \mathrm{F}$ & $66-77^{\circ} \mathrm{F}$ & M.O.P & $\mathrm{T}_{\mathrm{RA}}$ & $-2.3^{\circ} \mathrm{F}, \mathrm{RA}$ \\
\hline T-3 & $\mathrm{T}_{\mathrm{RA},}+3^{\circ} \mathrm{F}$ & $50-60^{\circ} \mathrm{F}$ & $60-80^{\circ} \mathrm{F}$ & 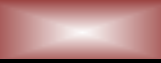 & & \\
\hline T-4 & $\mathrm{T}_{\mathrm{RA},}+5^{\circ} \mathrm{F}$ & $45-50^{\circ} \mathrm{F}$ & $75-80^{\circ} \mathrm{F}$ & 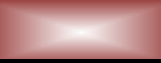 & & \\
\hline T-5a & $\mathrm{T}_{\mathrm{RA},}-5^{\circ} \mathrm{F}$ & $53-57^{\circ} \mathrm{F}$ & $70-72^{\circ} \mathrm{F}$ & M.O.P & $T_{R A}$ & $-4.2^{\circ} \mathrm{F}, \mathrm{RA}$ \\
\hline$T-5 b$ & $\mathrm{~T}_{\mathrm{RA},}-5^{\circ} \mathrm{F}$ & $49-51^{\circ} \mathrm{F}$ & $70-75^{\circ} \mathrm{F}$ & M.O.P & $\mathrm{T}_{\mathrm{MA}}$ & $+3.8^{\circ} \mathrm{F}, \mathrm{MA}$ \\
\hline T-6 & $\mathrm{T}_{\mathrm{RA},}, 8^{\circ} \mathrm{F}$ & $53-59^{\circ} \mathrm{F}$ & $67-77^{\circ} \mathrm{F}$ & Temp & $T_{R A}$ & $-7.5^{\circ} \mathrm{F}, \mathrm{RA}$ \\
\hline $\mathrm{T}-7$ & $\mathrm{~T}_{\mathrm{RA},}+8^{\circ} \mathrm{F}$ & $49-51^{\circ} \mathrm{F}$ & $64-66^{\circ} \mathrm{F}$ & M.O.P & $T_{R A}$ & $+9.0^{\circ} \mathrm{F}, \mathrm{RA}$ \\
\hline T-8a & $\mathrm{T}_{\mathrm{OA},}+8^{\circ} \mathrm{F}$ & $56-58^{\circ} \mathrm{F}$ & $70-74^{\circ} \mathrm{F}$ & 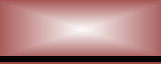 & & \\
\hline$T-8 b$ & $\mathrm{~T}_{\mathrm{OA},}+8^{\circ} \mathrm{F}$ & $45-53^{\circ} \mathrm{F}$ & $70-75^{\circ} \mathrm{F}$ & 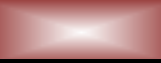 & & \\
\hline T-9 & $\mathrm{T}_{\mathrm{OA},}-8^{\circ} \mathrm{F}$ & $56-58^{\circ} \mathrm{F}$ & $70-72^{\circ} \mathrm{F}$ & 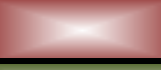 & & \\
\hline T-10 & $\mathrm{T}_{\mathrm{MA},}+8^{\circ} \mathrm{F}$ & $48-53^{\circ} \mathrm{F}$ & $70-74^{\circ} \mathrm{F}$ & M.O.P & $\mathrm{T}_{\mathrm{MA}}$ & $+6.6^{\circ} \mathrm{F}, \mathrm{MA}$ \\
\hline
\end{tabular}


In the "Proactive Diagnostics" column of Table 2, the temperature sensor that was identified as being at fault (if a fault was detected passively) is identified. In the "Fault Correction" column of Table 2, the magnitude of the constant bias correction to the sensor identified as faulty is displayed. In each of the last three columns, green shading is used to indicate stages of each test that produced the desired result and red shading is used to indicate stages that produced incorrect results. The incorrect result could be caused by either a lack of robustness in the SCC algorithms, or, in the case of some undetected faults, a fault severity below the limits for detection.

The first test performed was a baseline test in which no faults were present. It was performed to verify that no faults would be detected when none were instigated. This test was run for 16 hours. Despite some sharp oscillations in the return-air temperature, no faults were detected during the test. Figure 8 shows the mixing-box temperatures over the duration of the test. Solid lines in this plot identify the actual temperatures measured by the sensors, and dashed lines identify the virtual temperatures that the SCC program acts upon. In this case, because no faults were instigated, the two lines for each sensor overlap perfectly in Figure 8. During the baseline test, the mixed-air temperature always stayed safely within the bounds of the outdoorand return-air temperatures, creating no risk of a fault being detected in the passive test.

Figure 9 shows the virtual OAF, the measured OAF, and the damper command versus time for the baseline test. The damper command (black line) was held constant at 35 because at the minimum occupied position. The red lines represent the limits for detection of a fault for detection of a fault. These limits are based on the tolerances set for the temperature sensors, which are propagated through the OAF calculation (see Fernandez et al. 2009, Section 2.5), and thus are functions of the difference between the outdoor-air and return-air temperatures. The virtual OAF fluctuates during the test but always remains within the bounds for its expected value. The fluctuation is attributable to a delayed transient response of the OAF to changes in the driving conditions. A hypothesis potentially explaining this observed behavior of the OAF is that the measured transient response is affected by the use of two different types of temperature sensors (the averaging sensor for the mixed-air temperature, and the single-point probe-type sensors elsewhere), which respond at different rates. The averaging sensor may respond to changes in air temperature faster than the probe-type sensor, leading to fluctuations in the calculated OAF as driving conditions change. This hypothesis requires testing in future work to better understand the observed behavior.

Figure 10 shows the progression of fault detection, diagnosis, and correction for T- 7 in which a return-air temperature sensor bias fault of $+8^{\circ} \mathrm{F}$ is present, leading to successful correction of the fault. Vertical lines labeled with numbers above the plot identify key events in the process. As done in Figure 8, the damper position is shown for comparison to the temperature responses. At the onset of the test, the system operated with all sensors reading the correct values, and with no bias instigated. The damper system was in the minimum occupied position, with a damper command signal of 35 . At point 1 (vertical line), an $8^{\circ} \mathrm{F}$ positive bias was instigated in the return-air sensor (i.e., the virtual return-air sensor). At this point, the virtual return-air temperature (dashed red line) increase $8^{\circ} \mathrm{F}$ above the measured return-air reading because it now has a fault. At point 2, a fault is detected in the minimum occupied position 


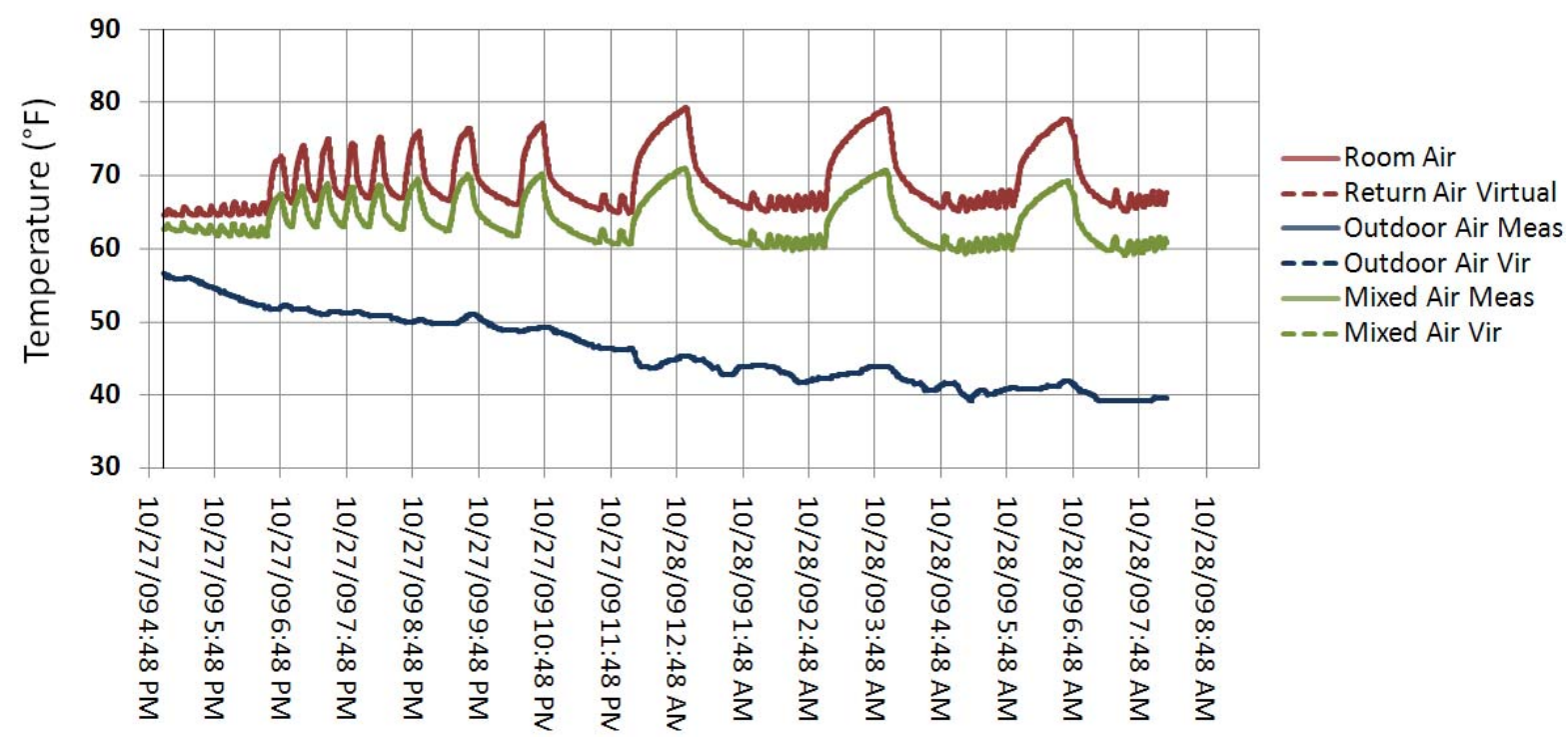

Figure 8: Baseline test - temperatures.

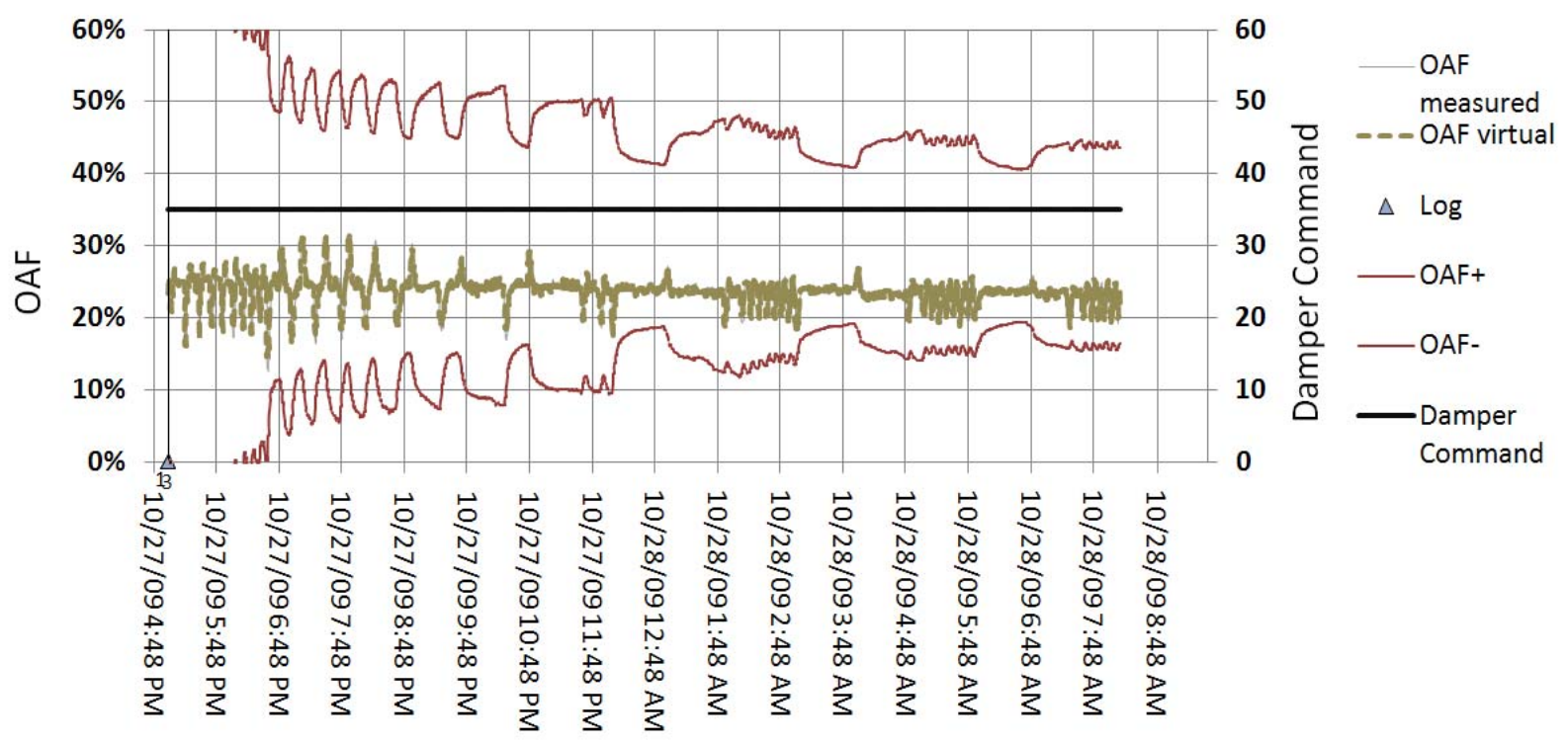

Figure 9: Baseline test - OAF and damper command.

passive test because the virtual OAF is $53 \%$, which is greater than upper limit for fault detection of $43 \%$ at that time. The system was running in automatic mode, so immediately following detection of a fault, the proactive diagnostic test began. The OA damper was commanded to 0 (completely closed outdoor-air damper), the program waited until steady state was reached and then determined that the mixed- and return-air temperatures were not close enough to be considered equal. At this point (point 3), the damper signal was commanded to 100 (fully open outdoor-air damper) and when steady state was reached, the program determined that the outdoor-air and mixed-air temperatures were close enough to be considered equal. This led to 
the conclusion that the mixed-air sensor was faulty (i.e., the fault was isolated to an individual sensor). The, at point 4 , the fault characterization and correction processes began. The damper was commanded to 0 , and steady state was reached at point 5 . The SCC process then recorded the differences between the mixed- and return-air virtual temperature measurements to determine if the bias was approximately constant over time, which it was. The SCC program then averaged the measured differences in temperature between the (virtual) mixed- and returnair sensors, and used this difference to apply a correction to (i.e., effectively recalibrate) the (virtual) return-air sensor. The SCC program determined the bias to be $8.98^{\circ} \mathrm{F}$, nearly $1^{\circ} \mathrm{F}$ above the actual $8^{\circ} \mathrm{F}$ bias fault that was implemented. At point 6 , the fault correction ended, the corrected bias was applied to the virtual return-air temperature, and the system returned to normal operation at the minimum occupied damper position. The entire process took approximately 1 hour.

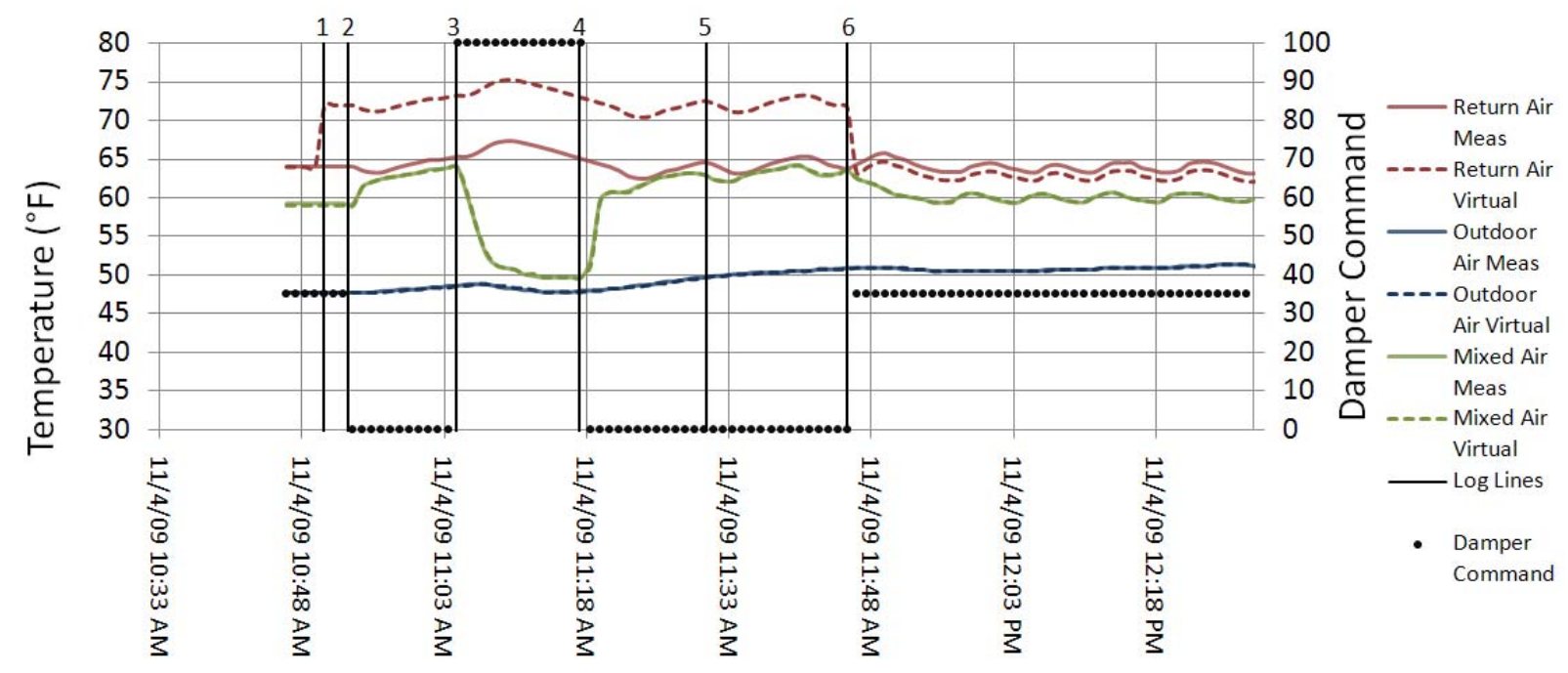

Figure 10: Test T-7-- detection, diagnosis and correction of a biased return-air temperature sensor.

Tests $\mathrm{T}-1$ and $\mathrm{T}-3$ featured biases of $-3^{\circ} \mathrm{F}$ and $+3^{\circ} \mathrm{F}$ in the return-air (virtual) temperature sensor, with $2^{\circ} \mathrm{F}$ tolerances applied to all temperature sensors. The results of these two tests clearly showed that a bias severity of $3^{\circ} \mathrm{F}$ was too small to detect with the algorithms at the current tolerance magnitude of $2^{\circ} \mathrm{F}$. Figure 11 shows the mixing box temperatures during Test $\mathrm{T}-1$. The decrease in the virtual return-air temperature caused by instigation of the bias fault was not sufficient to decrease it below the virtual mixed-air temperature that a temperaturesensor fault was detected by the passive test.

Driving conditions have an important effect on the minimum severity detectable by the passive test for temperature-sensor faults. During the baseline test with no fault present, the outdoor-air and return-air temperatures were only about $9^{\circ} \mathrm{F}$ apart at the beginning of the test (see Figure 8). Consequently, at a damper signal of 35 for the minimum occupied position, only about a $2^{\circ} \mathrm{F}$ difference existed between the return-air and the mixed-air temperatures. Under these conditions, $\mathrm{a}-3^{\circ} \mathrm{F}$ bias in the return-air sensor would have been sufficient to decrease the virtual 
return-air temperature below the virtual mixed-air temperature; however, accounting for tolerances, this would not have been sufficient for detection of the fault. When this observation is compared to Figure 11, where the virtual return-air temperature remains 3 to $5^{\circ} \mathrm{F}$ above the mixed-air temperature, the large impact that actual ambient conditions can have on the limits for fault detection is evident. This effect is more pronounced for the passive test for detection of a temperature sensor fault. The minimum occupied position passive test, on the other hand, sets limits for fault detection that are a function of the outdoor- and return- air temperatures, so the driving conditions are less important, but as will be shown later, they still play an important role in determining the severity of a fault that can be detected.

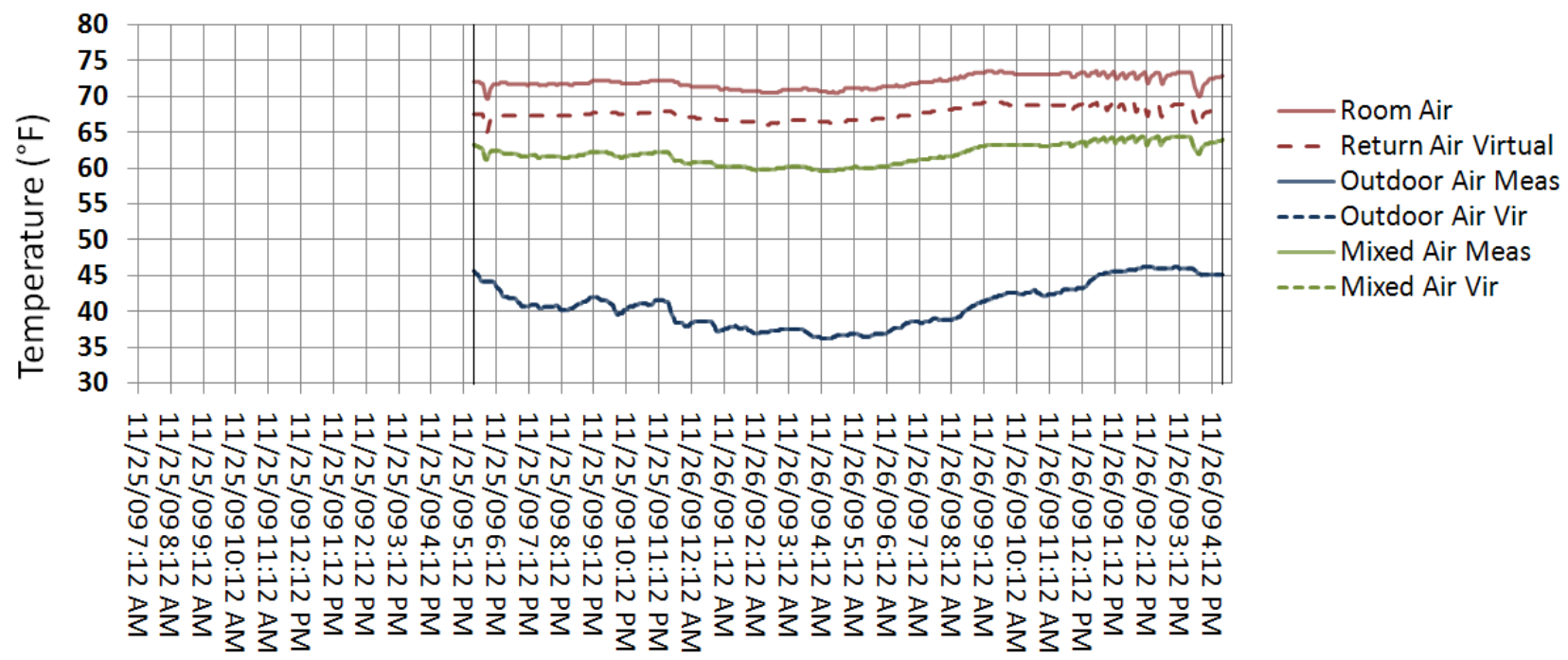

\section{Figure 11: Test T-1 -- Mixing Box Temperatures}

Figure 12 shows the actual measured OAF and the virtual OAF, as well as the OAF limits for fault detection during Test T-1. The virtual OAF remains almost steady at a level $5 \%$ above the lower limit for fault detection (line labeled OAF-). Unlike during the baseline test, the driving conditions were quite steady during Test T-1, which may have contributed to some degree to the virtual OAF never approaching the fault detection limits.

To investigate the ability of the algorithms to detect and correct the same fault under tighter temperature tolerances, the test for $a-3^{\circ} \mathrm{F}$ bias in the return-air temperature sensor was run but with $+/-1^{\circ} \mathrm{F}$ tolerances in for all temperature sensors (rather than $+/-2^{\circ} \mathrm{F}$ tolerances). The first time this test was run (Test T-2a), the fault was passively detected in the minimum occupied position test, with a virtual OAF of $17 \%$ and the lower limit for fault detection at $19 \%$. An incorrect isolation of the fault to the MA temperature sensor was made, however. Recall from the "Temperature and Damper Proactive Diagnostics" test process (Fernandez et al. 2009, Figures 3; see Appendix) that temperature sensor faults are isolated by comparing the mixed-air temperature to the return-air temperature with the OA damper completely closed, then comparing the mixed-air temperature to the outdoor-air temperature with the OA damper completely open. If the dampers are operating properly, four outcomes are possible from this test: 


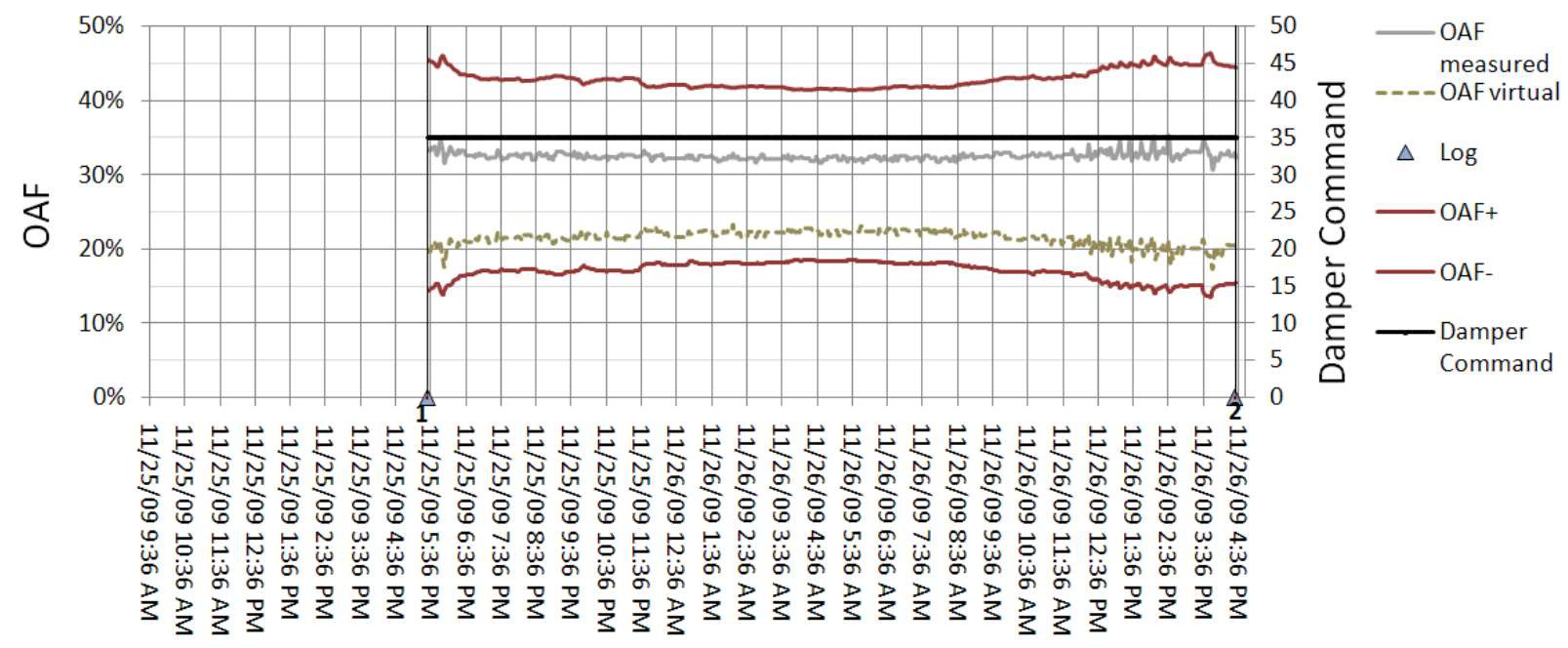

Figure 12: Test T-1 - OAF and Dampers

1) If the MA and the RA temperatures are equal within tolerances, and the MA and the $O A$ temperatures are not equal within tolerances, the fault is isolated to the outdoor-air sensor.

2) If the MA and RA temperatures are not equal within tolerances, and the MA and the OA temperatures are equal within tolerances, the fault is isolated to the return-air sensor.

3) If the MA and the RA temperatures are not equal within tolerances, and the MA and the OA temperatures are not equal within tolerances, the fault is isolated to the mixed-air sensor.

4) If the MA and the RA temperatures are equal within tolerances, and the MA and the OA temperatures are equal within tolerances, no temperature sensors are determined to be faulty, and instead the damper position is determined to be set incorrectly, according to the desired OAF.

The mixed-air and return-air temperatures were determined to not be equal when the test apparatus OA damper was fully closed. It was also determined that the mixed-air and outdoorair temperatures were not equal when the outdoor-air damper was fully open (the mixed-air temperature was 2.2 degrees higher than the outdoor-air temperature in this case). The differences were caused partly by the temperature tolerances being as small as they were. Another cause for the discrepancy between the mixed- and outdoor-air temperatures when they should have been approximately equal can be inferred from Figure 7 . Leakage when dampers are fully closed resulted in a minimum OAF of $10 \%$ at all times, including during the proactive diagnostic tests, which are designed to isolate the flows of outdoor and return air. If the outdoor-air and return-air temperature difference is $20^{\circ} \mathrm{F}$ during the proactive diagnostics, the $10 \%$ OAF associated with leakage when the outdoor-air damper is fully closed will cause a $2^{\circ} \mathrm{F}$ difference in these temperatures. Because the return-air damper also leaks when fully closed, the inverse is also true, so the maximum achievable OAF is around $90 \%$. Damper leakage is an important factor that is not handled by the existing algorithms, but which needs to be addressed 
in future versions to avoid incorrect diagnoses and attempted fault corrections. In the case of Test T-2a, the algorithms went on to incorrectly implement a "correct" the mixed-air sensor by attributing $\mathrm{a}+2.3^{\circ} \mathrm{F}$ bias correction to the mixed-air temperature sensor (see Table 2 ). This same test was rerun with slightly different temperatures as Test T-2b. In this case, the proactive diagnostics reached the correct conclusion, and the return-air sensor was subsequently corrected by $2.3^{\circ} \mathrm{F}$.

The same problem that plagued Test T-2a also led to the incorrect diagnosis of a mixed-air temperature sensor fault in Test T-5b. Although there were $2^{\circ} \mathrm{F}$ tolerances applied to this test, the same incorrect decision was made that the mixed-air and outdoor-air temperatures were not close enough to being equal during the proactive diagnostics with a fully open outdoor-air damper. In this case, the problem was caused by the difference between the outdoor- and return-air temperatures being even greater than in Test T-2a. The solution to this problem should be the same, however -- the diagnostics need to account for normal damper leakage.

The return-air temperature sensor tests seemed to indicate that with $2^{\circ} \mathrm{F}$ temperature sensor tolerances, the threshold for detection of a temperature sensor bias fault is about $5^{\circ} \mathrm{F}$. One test was performed on the mixed-air sensor at a high fault severity level of $8^{\circ} \mathrm{F}$, and the fault was detected and corrected. For the outdoor-air temperature sensor, however, even at the $8^{\circ} \mathrm{F}$ level of fault severity, the fault remained undetected for both a positive and negative instigated biases. Understanding the reason for the lack of detection requires examining details of the rules for fault detection.

The temperature sensor passive fault detection test itself is somewhat limited. It requires the right set of conditions such that an instigated temperature-sensor bias will produce a set of virtual temperatures for which the mixed-air temperature is outside the range between the outdoor-air and return-air temperatures (and by enough to conclusively determine that a fault exists, considering sensor tolerances). Indeed, the passive temperature sensor test was only versatile enough to correctly detect one fault during the 13 temperature sensor bias tests that were performed. The passive test for the minimum occupied position, on the other hand, is much more versatile, because it is a relative test. It only requires that the virtual OAF differ substantially from the expected value of the OAF. This test, however, has its own limitations, especially in detecting outdoor-air sensor faults. Outdoor-air sensor biases cause a proportionately smaller change in the OAF, compared to biases in the mixed-air and the returnair sensors. The outdoor-air temperature appears only in the denominator of the OAF equation. It is, therefore, difficult to distinguish a deviation from the normal OAF that is caused by an outdoor-air bias from one that is caused by normal variations. Figure 13 through Figure 18 show the intrinsic level of fault severity necessary to detect either positive or negative bias faults in each of the three sensors. The term 'intrinsic level' means (in this case) "in the absence of any transient behavior, sensor noise, or other factors that might influence the ability to detect a fault." These plots are valid for a return-air temperature of $70^{\circ} \mathrm{F}$ (approximate room temperature), an actual OAF of $30 \%$, and $+/-2^{\circ} \mathrm{F}$ tolerances for all sensors. The darker shading in each plot identifies regions of intrinsic fault detection ability. Figure 17 and show that for detection of bias faults in mixed-air temperature sensors, the threshold of fault severity for detection is between 3 and $5^{\circ} \mathrm{F}$, the precise value of the threshold depending on the 
temperature and the sign of the bias. For return-air temperature sensors, the threshold is between 4 and $6^{\circ} \mathrm{F}$ for most conditions, as shown in Figure 15 and Figure 16. For outdoor-air sensors, however, the threshold is generally greater than $8^{\circ} \mathrm{F}$, and more typically in the range of 12 to $15^{\circ} \mathrm{F}$ (see Figure 13 and Figure 14). This represents a limitation of the fault detection algorithms for which there may be no easy solution without changing the underlying method.

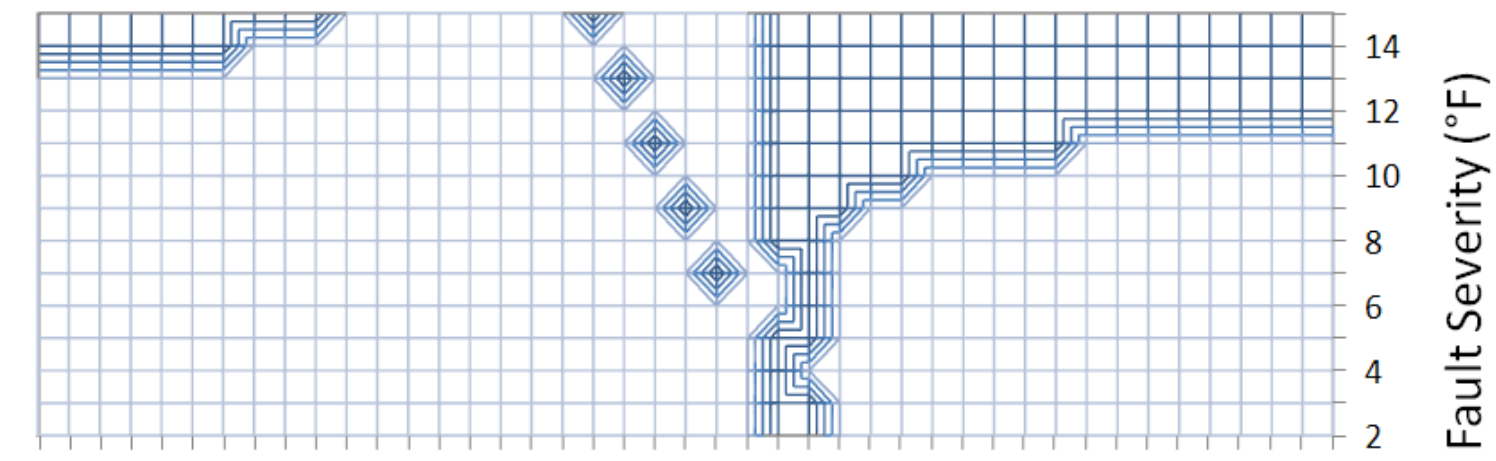

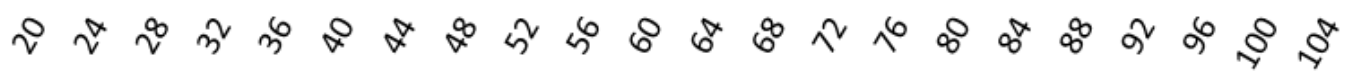 Outdoor Air Temperature $\left({ }^{\circ} \mathrm{F}\right)$}

Figure 13: Intrinsic level of fault severity necessary to detect positive bias faults in OA temperature sensors using the minimum occupied position passive test.
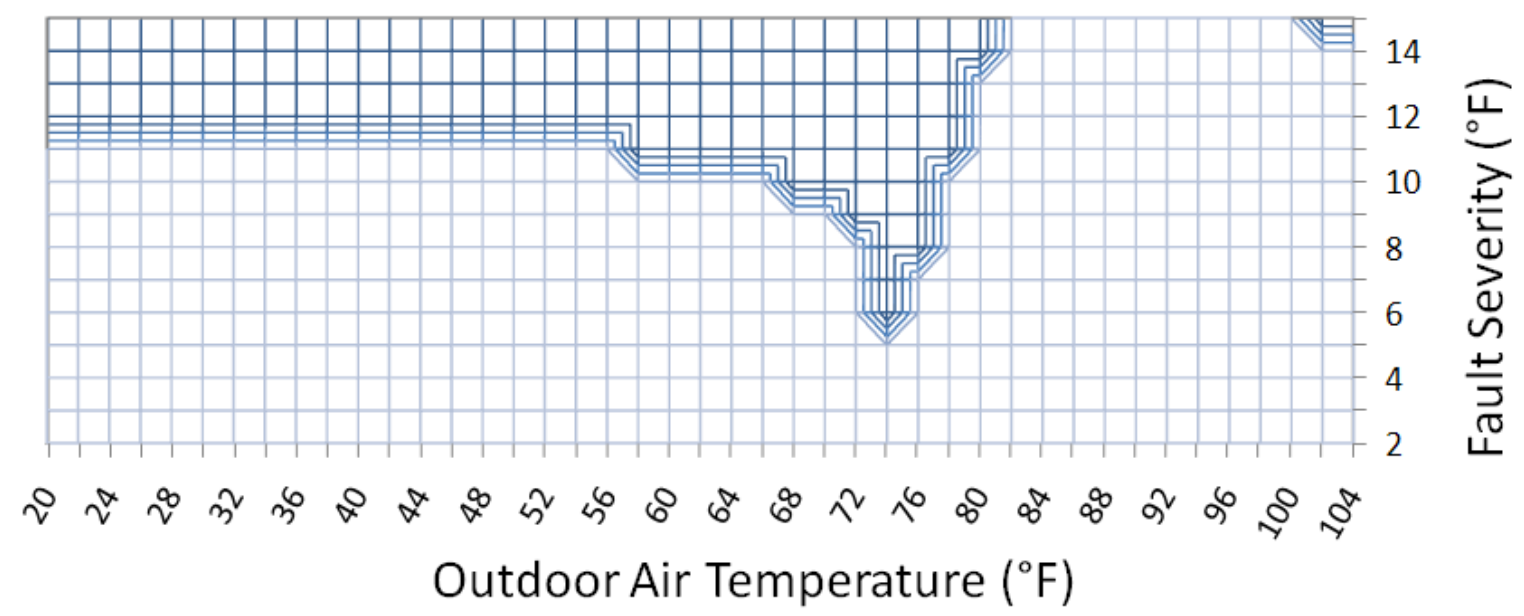

Figure 14: Intrinsic level of fault severity necessary to detect negative bias faults in OA temperature sensors using the minimum occupied position passive test. 


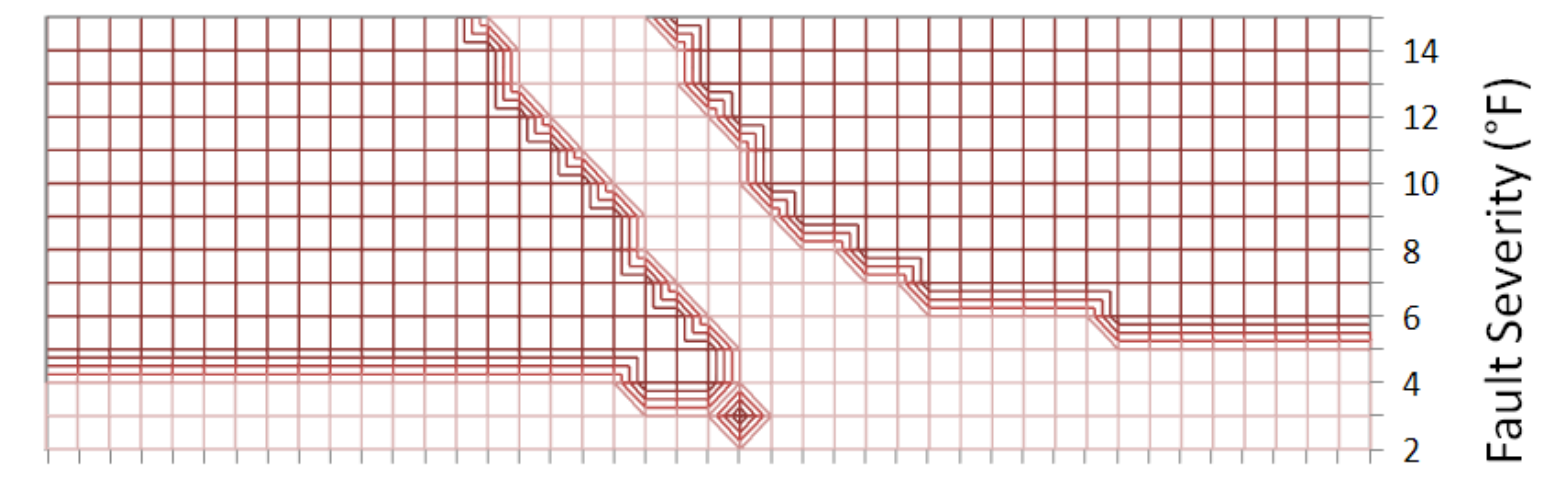

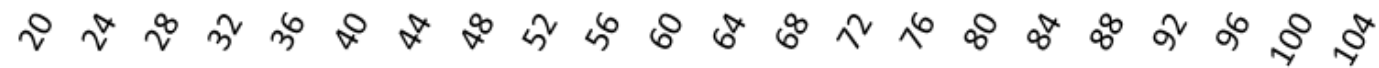 Outdoor Air Temperature $\left({ }^{\circ} \mathrm{F}\right)$}

Figure 15: Intrinsic level of fault severity necessary to detect positive bias faults in RA temperature sensors using the minimum occupied position passive test.

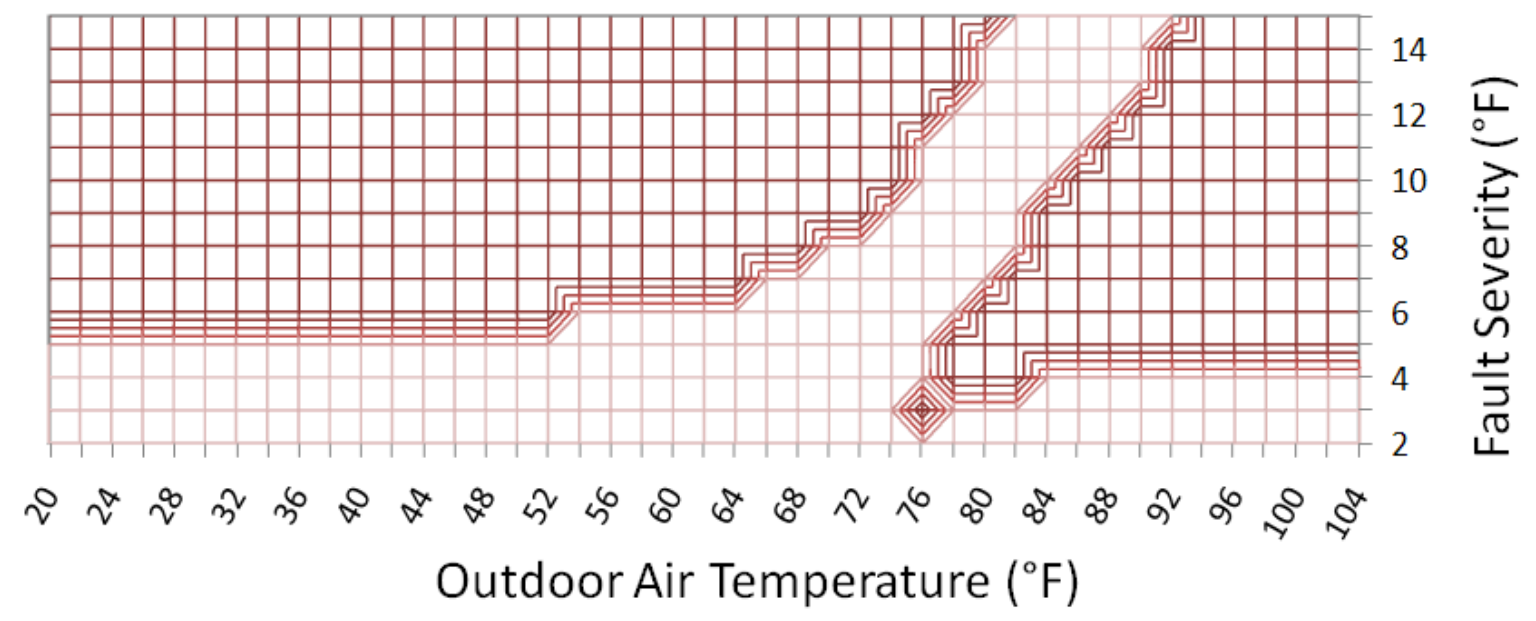

Figure 16: Intrinsic level of fault severity necessary to detect negative bias faults in RA temperature sensors using the minimum occupied position passive test. 


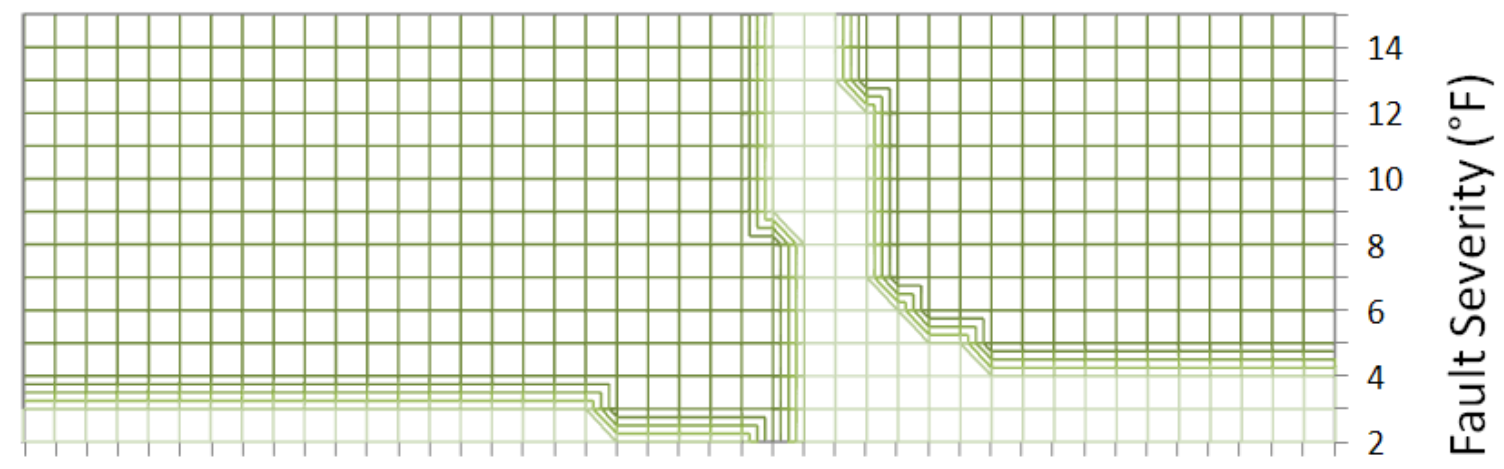

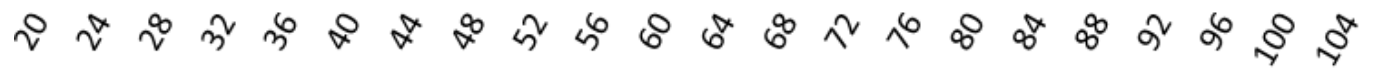 Outdoor Air Temperature $\left({ }^{\circ} \mathrm{F}\right)$}

Figure 17: Intrinsic level of fault severity necessary to detect positive bias faults in MA temperature sensors using the minimum occupied position passive test.
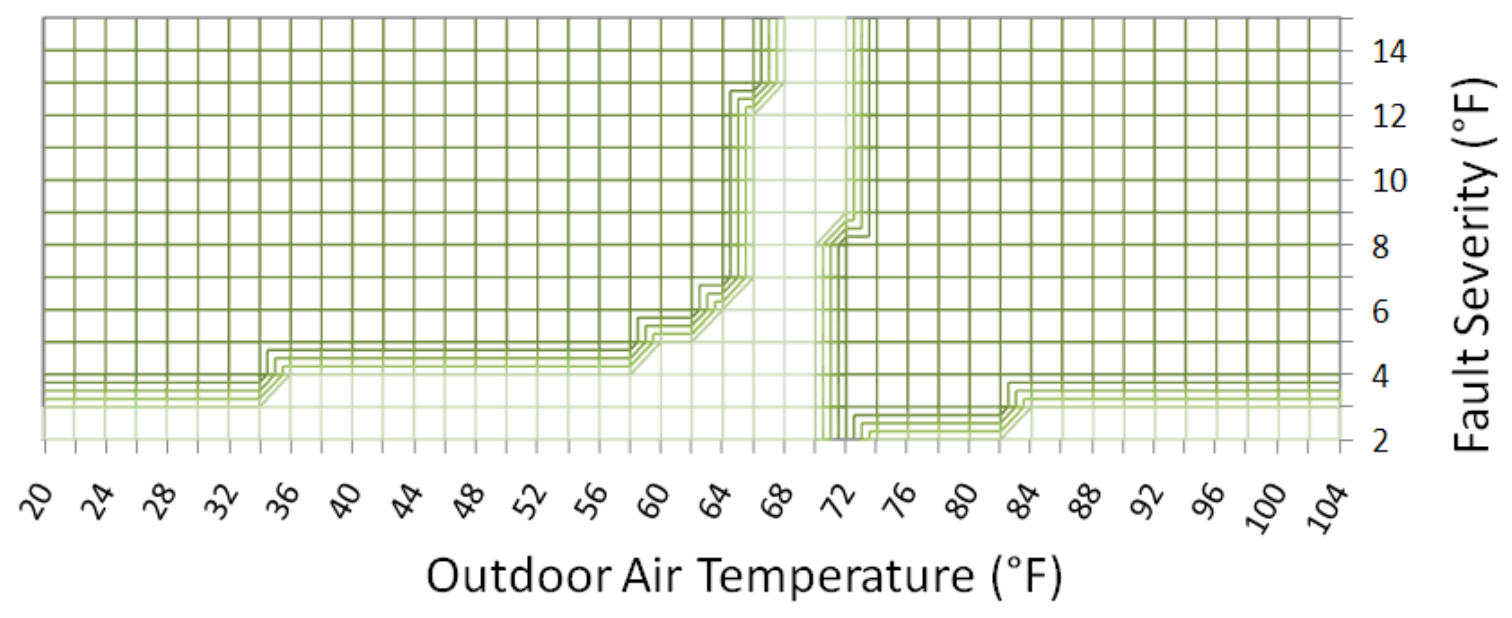

Figure 18: Intrinsic level of fault severity necessary to detect negative bias faults in MA temperature sensors using the minimum occupied position passive test.

\subsection{Relative Humidity Sensor Bias Tests}

Table 3 shows the results of the relative humidity sensor bias tests. Three tests were performed to validate the ability of the algorithms to successfully detect and correct bias faults of constant magnitude in $\mathrm{RH}$ sensors and to investigate the relationship between severity of the $\mathrm{RH}$ sensor bias and the ability to detect the faults. Faults were instigated in the mixed-air RH sensor for these tests. While this is by no means a comprehensive set of tests, it verifies that the algorithms do work for $\mathrm{RH}$ sensors and provides a good starting point for understanding relationship between fault severity and fault detection. Also, because the formulation of $\mathrm{RH}$ algorithms for each of the three stages of the process is fundamentally similar to formulation of the temperature sensor algorithms, some of the issues identified as areas requiring improvement for temperature sensors also apply to the relative humidity sensor tests. 
Table 3: Results of relative humidity sensor tests.

\begin{tabular}{|c|c|c|c|c|c|c|}
\hline Test \# & $\begin{array}{c}\text { Sensor and } \\
\text { Severity }\end{array}$ & Outdoor Air RH & Return Air RH & $\begin{array}{c}\text { Passive } \\
\text { Detction }\end{array}$ & $\begin{array}{c}\text { Proactive } \\
\text { Diagnostics }\end{array}$ & $\begin{array}{c}\text { Fault } \\
\text { Correction }\end{array}$ \\
\hline $\mathrm{RH}-1$ & $\mathrm{RH}_{\mathrm{MA}},-10 \%$ & $30-50 \%$ & $3-5 \%$ & & & \\
\hline $\mathrm{RH}-2$ & $\mathrm{RH}_{\mathrm{MA}},-20 \%$ & $55-70 \%$ & $\sim 25 \%$ & $\mathrm{RH}$ & $\mathrm{RH}_{\mathrm{MA}}$ & $-\mathbf{1 3 . 5 \%}$ \\
\hline $\mathrm{RH}-3$ & $\mathrm{RH}_{\mathrm{MA}},-30 \%$ & $30-50 \%$ & $15-20 \%$ & $\mathrm{RH}$ & $\mathrm{RH}_{\mathrm{MA}}$ & $-\mathbf{2 5 . 5 \%}$ \\
\hline
\end{tabular}

The three tests were at three different levels of sensor-bias severity: $-10 \%,-20 \%$ and $-30 \%$. The $-10 \%$ bias error was not detected. The $-20 \%$ and $-30 \%$ bias errors were successfully detected and isolated. The $-30 \%$ bias was corrected reasonably well with a correction of $25.5 \%$ our of the ideal correction of $30 \%$, while the $-20 \%$ bias in Test $\mathrm{RH}-2$ was corrected by with a substantial difference between the correction of $13.5 \%$ and the magnitude of the actual fault (indicated by yellow shading rather than green used for good corrections), which was $30 \%$.

There are three key variables related to humidity that are tracked during the passive diagnostic tests for RH sensor faults, relative humidity itself, absolute humidity, and enthalpy. Each of these variables is treated the same way that temperature is for the temperature sensor passive fault test. The mixed-air sensor is checked to ensure that its value is between the values from the outdoor- and return-air sensors (again, accounting for tolerances). In the case of absolute humidity and enthalpy, their values are calculated using the values of virtual $\mathrm{RH}$ and values of the virtual temperatures.

Figure 19 shows the limits for fault detection at the time of fault detection for Test RH-2. The figure shows that the fault was detected because the value of the mixed-air $\mathrm{RH}$ was outside of the allowable range between the outdoor-air and return-air RHs. The absolute humidity was also outside the range between the outdoor- and return-air sensors, but not by quite enough to trigger a fault by itself, when tolerances are considered. The enthalpy of the mixed-air sensor remained bound by the values of enthalpy based on the outdoor- and return-air sensors. Figure 20 shows the same limits for Test RH-3. At the time of detection, both the relative and absolute humidities were outside the acceptable limits, leading to detection of the fault. 


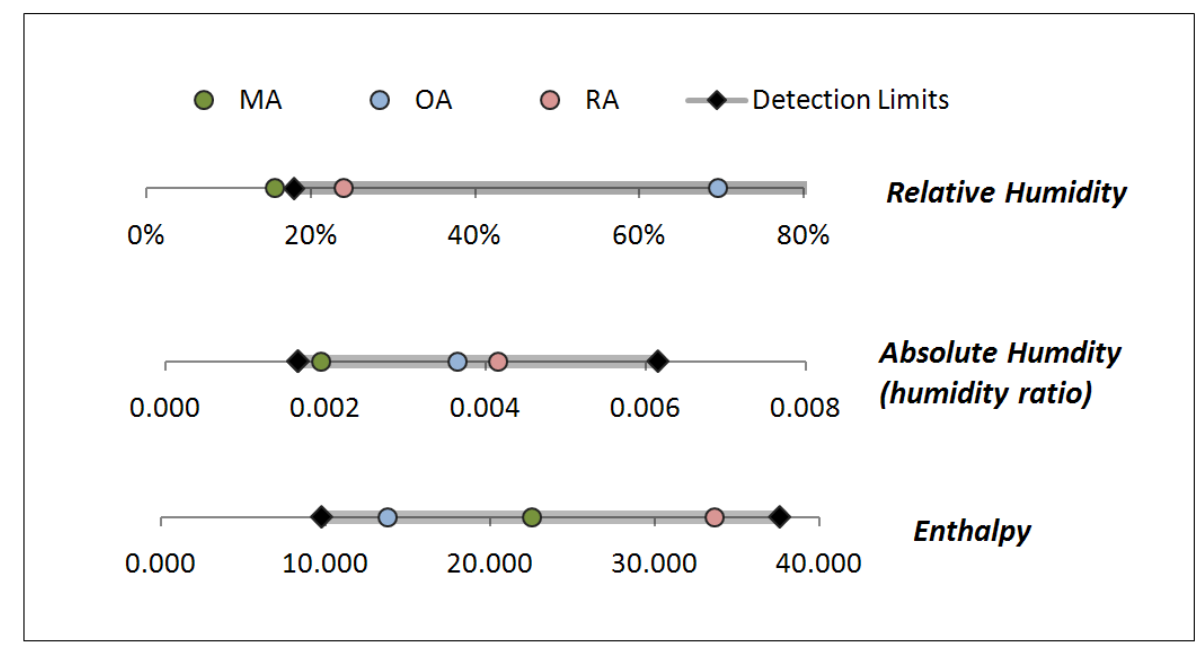

Figure 19: Test RH-2: Key variables for fault detection

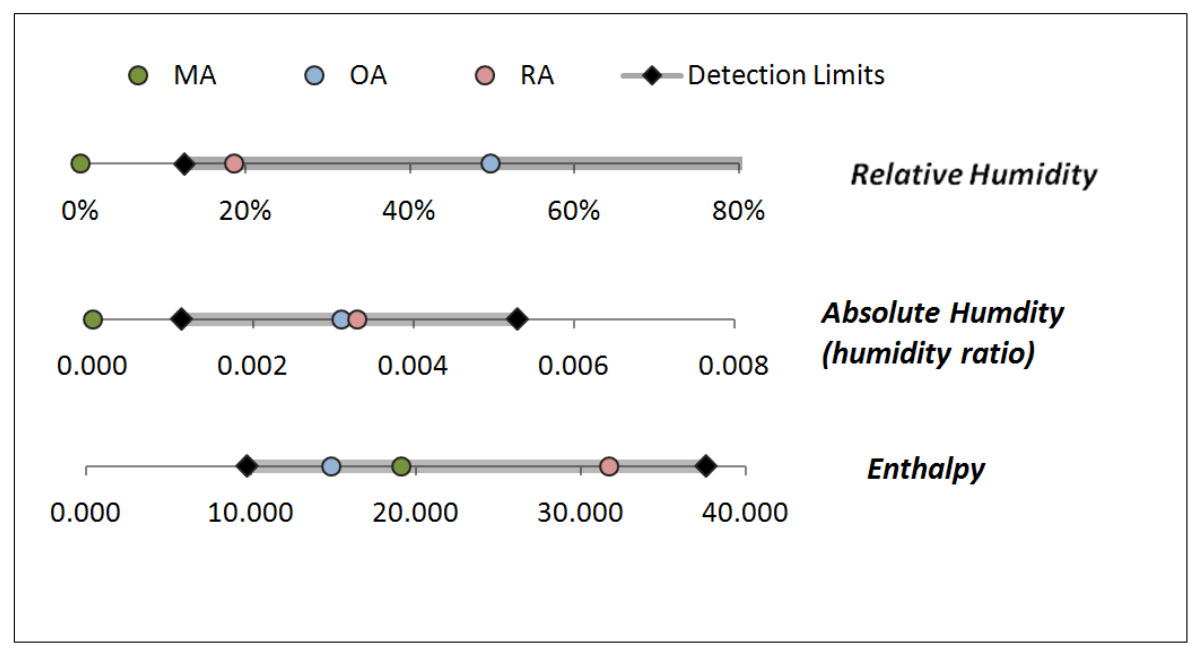

Figure 20: Test RH-3: Key variables for fault detection

Figure 21 shows the process of fault detection, diagnosis and evaluation/correction for the $\mathrm{RH}-2$ Test. The format of Figure 21 is identical to that of Figure 10, except that the key variables are relative humidities, rather than temperatures. Note also that the six labeled vertical lines each correspond to the same points in the overall diagnostic process as the similar labels in Figure 10. There are two subtle differences between how the relative humidity appears to behave, relative to the temperature during this process. First, the relative humidity sensors appear slower in sensing changes in the relative humidity than the temperature sensors are in sensing changes in temperature. When the outdoor-air damper was fully open during the proactive diagnostics (point 3), a half hour was required for the mixed-air $\mathrm{RH}$ sensor to reach steady state, compared to about 12 minutes for the mixed-air temperature sensor to reach steady state. Second, the mixed-air relative humidity does not closely approach either the outdoor-air sensor $\mathrm{RH}$, when the OA damper is $100 \%$ open, or the return-air sensor $\mathrm{RH}$, when the OA damper is completely closed. The differences are substantial (compare the solid green line in Figure 21 to the solid red line at point three and blue line at point 4) and have important implications in the 
proactive diagnostics for the ability to determine whether the mixed-air $\mathrm{RH}$ is close enough to being equal to the outdoor/return-air $\mathrm{RH}$, and also in the fault correction. Recall from Fernandez et al. (2009) that the fault correction process for temperature and relative humidity works by calibrating the faulty sensor to one of the working sensors. While the temperature sensors were all able to be corrected to within the tolerance of the sensor, the humidity sensors were not corrected to within tolerance. The correction for Test $\mathrm{RH}-2$ was particularly inaccurate (and is shaded yellow in Table 3 to indicate the resulting substantial difference between the correction and the actual magnitude of the bias error). The solution to this problem is likely the same solution as proposed for the temperature sensor process, to develop a method to account for damper leakage in all stages of the SCC process.

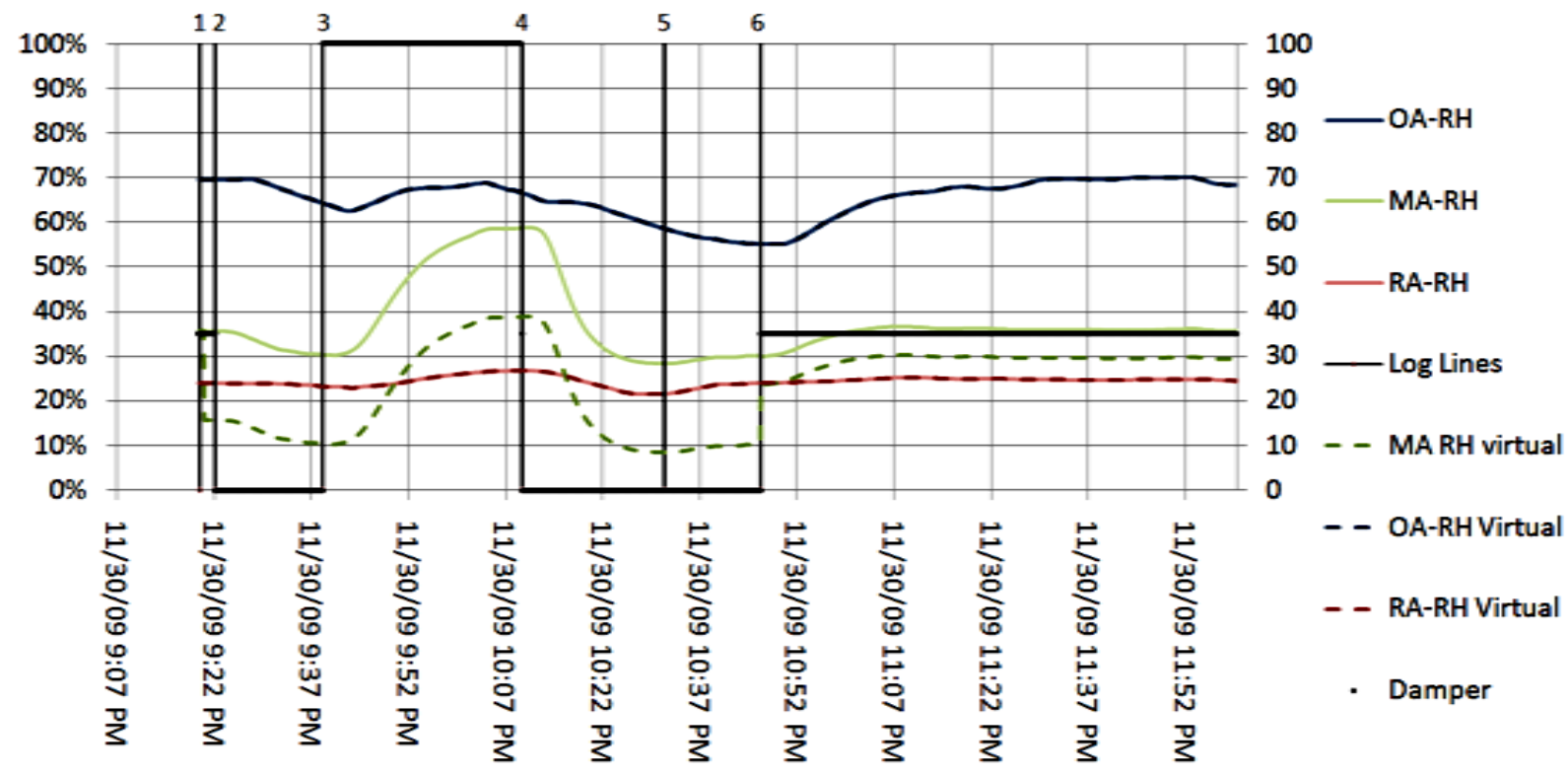

Figure 21: Test RH-2 -- detection, diagnosis and correction for a -20\% RH bias in the relative humidity sensor.

In these series of tests, negative mixed-air biases were chosen for testing rather than positive mixed-air biases for evaluating the algorithms because, a mixed-air $\mathrm{RH}$ that is above both an outdoor-air and a return-air RHs is not sufficient to detect the fault with the current algorithms. The decision to exclude this condition from the set of rules for $\mathrm{RH}$ fault detection is that it is possible for mixed-air $\mathrm{RH}$ to be higher than $\mathrm{OA}$ and $\mathrm{RA}$ relative humidities. For example, mixing equal parts of air at $40 \% \mathrm{RH}$ at $68^{\circ} \mathrm{F}$ with air at $40 \% \mathrm{RH}$ at $32^{\circ} \mathrm{F}$ yields a mixed-air stream at $48 \% \mathrm{RH}$, higher than both the constituent streams. But there is no reason to conclude that because this effect is possible, any mixed-air temperatures higher than the outdoor- and returnair RHs should be screened out automatically. Therefore, further development of the RH fault detection algorithms is needed to address this issue and produce a more robust set of algorithms for detection of $\mathrm{RH}$ sensor faults. 


\subsection{Minimum Occupied Damper Position Faults}

Table 4 shows the results of the three tests performed to test the algorithms for detecting and correcting faults in the minimum occupied position for the outdoor-air damper. These are faults wherein the damper is fully functional, but the damper command signal at minimum occupied position is too high or too low to achieve the desired minimum occupied position. Because much of the time, the air handler will operate at the minimum occupied position, this is an important fault to detect and correct during operation. For example, during commissioning, the building operator may want to set up the system to provide $25 \%$ outdoor air at the minimum occupied position and assume that a damper command signal of 25 will achieve that desired OAF. Most dampers do not operate linearly, so this could be a poor assumption. For example, If the outdoor-air damper responded to command signals similarly to the lab system (see Figure 7 ), the damper at command signal of 25 would only allow enough outdoor air for an OAF=16\%, much less than the desired $25 \%$.

Table 4: Test results for incorrectly set minimum occupied position

\begin{tabular}{|c|c|c|c|c|c|c|}
\hline Test \# & $\begin{array}{c}\text { Initial M.O.P. } \\
\text { damper setting }\end{array}$ & Outdoor Air T & Return Air T & $\begin{array}{c}\text { Passive } \\
\text { Detction }\end{array}$ & $\begin{array}{c}\text { Proactive } \\
\text { Diagnostics }\end{array}$ & $\begin{array}{c}\text { Fault } \\
\text { Correction }\end{array}$ \\
\hline MOP-1 & damper $=50$ & $30-45^{\circ} \mathrm{F}$ & $70-75^{\circ} \mathrm{F}$ & & & \\
\hline MOP-2 & damper $=20$ & $35-42^{\circ} \mathrm{F}$ & $69-75^{\circ} \mathrm{F}$ & M.O.P & $\mathrm{T}_{\mathrm{MA}}$ & $-5.2^{\circ} \mathrm{F}, \mathrm{MA}$ \\
\hline MOP-3 & damper $=20$ & $35-43^{\circ} \mathrm{F}$ & $69-76^{\circ} \mathrm{F}$ & M.O.P & M.O.P & damper=35 \\
\hline MOP-4 & damper $=65$ & $38^{\circ} \mathrm{F}$ & $70-75^{\circ} \mathrm{F}$ & M.O.P & M.O.P & damper=32.5 \\
\hline
\end{tabular}

The SCC program prompts the user during setup for the desired OAF at the minimum occupied position. For testing, we chose a desired OAF of $30 \%$. From Figure 7, we know that this system achieves around $30 \%$ OAF at a damper command signal of about 35 . Tests MOP-1, and MOP-2 assume that the user chose an initial damper command signal for minimum occupied position that deviated from the correct setting by +15 and -15 , respectively. With an initial damper command setting of 50 for the minimum occupied position, no fault was detected in Test MOP-1. This result is caused by the measured OAF remaining between $35 \%$ and $40 \%$ for a damper signal of 50 , which is too close to the desired OAF of $30 \%$ for the SCC program to conclude that a fault is present (accounting for the tolerances in the temperature sensors). Because the overestimated damper command signal for the minimum occupied position does not have a large effect on OAF, there should be a small performance penalty associated with the fault. In contrast, in test MOP-2, for which the damper command signal at minimum occupied position was set to the faulty value of 20 yielded a much greater effect on the OAF (recall that for this system, the OA damper remains completely shut until the damper command is increased above 20). During this test, the fault was detected in the passive test for faults in the minimum occupied position. Although correctly detected, the fault was incorrectly isolated to a bias in the mixed-air temperature sensor in the proactive diagnostic test. The incorrect diagnosis was associated with damper leakage, the same cause as for incorrect diagnoses of 
temperature sensor faults reported in Section 5.1. Likewise, the solution is to account for damper leakage in the SCC algorithms.

The algorithms performed correctly when the temperature sensor tolerances were increased from $2^{\circ} \mathrm{F}$ to $3^{\circ} \mathrm{F}$, effectively compensating for the damper leakage (MOP-3 in Table 4). Increasing these tolerances also raises the thresholds for fault detection in the minimum occupied position passive test. For test MOP-3, with an initial damper command signal of 20 , the fault is severe enough to be detected and, with the larger tolerances, the SCC program diagnoses (i.e., isolates) the fault correctly as an incorrectly set damper command for the minimum occupied position. Figure 22 shows the damper command and OAF throughout Test MOP-3. Initially, with the damper command of 20 , the measured OAF ranges from $6-8 \%$, which is well below the lower limit for fault detection (about $16 \%$ at the time, indicated by the red lines on the figure). At point 1, the SCC program detects the fault and begins the diagnostic process, setting the damper command first to 0 and then to 100. At point 2, with a diagnosis of a minimum occupied position fault, the program begins the fault correction process. This process is described in Fernandez et al. (2009), Section 2.3, and shown in Figure 23 of that report (see the Appendix of this report). When the correction process began in test MOP-3, a new damper position command is estimated by bisecting damper command interval between the initial damper signal of 20 and the maximum command signal of 100 to yield a new value for the command of 60 . At 60 , the OAF was too high (41\%) at steady state, so the process continued by bisecting the interval from 20 to 60 to obtain a revised command signal estimate of 40 , which it implemented. At steady state with the damper command at 40 , the signal was still too high (36\%), so the SCC process bisected the command interval between 20 and 40 to obtain a value of 30 , which it then implemented. At steady state with the damper command at 30, the OAF was too low at $24 \%$, so the process again refined the command estimate by bisecting the interval from 30 to 40, obtaining a new command estimate of 35 , which it implemented. Finally with the command at 35 , the OAF was $30 \%$ within acceptable tolerances, the desired minimum occupied position OAF. The fault correction process concluded by resetting the damper command signal at minimum occupied position to the value of 35 . After point 3 , the system returned to normal automatic operation. 


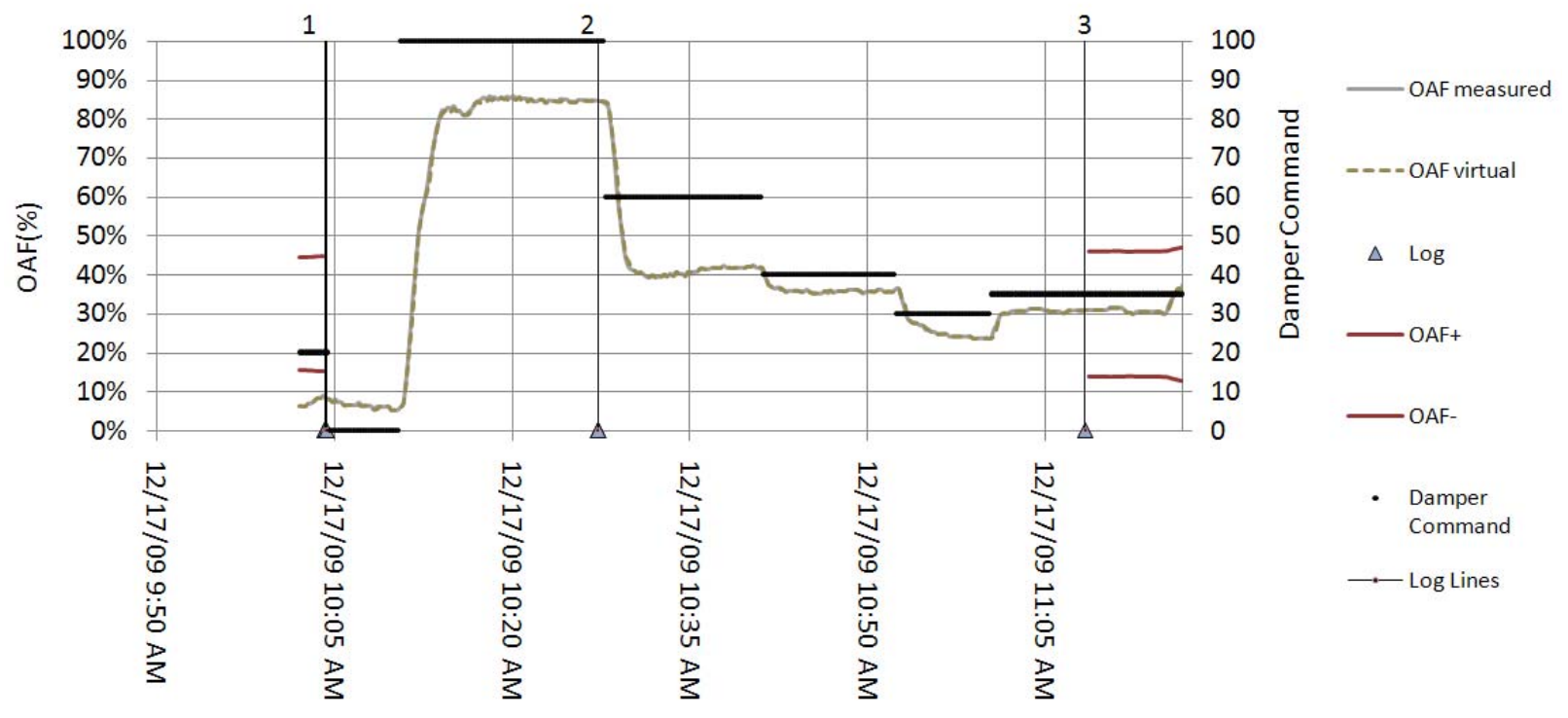

Figure 22: Damper position signal and OAF during Test MOP-3.

Test MOP-4 featured the same $3^{\circ} \mathrm{F}$ temperature sensor tolerances, but with an initial damper command signal at minimum occupied position of 65 . The fault was detected, diagnosed correctly, and corrected to a new damper command signal of 32.5 . 


\section{Conclusions}

The tests performed have provided important validation that the rule-based algorithms developed for self-correcting controls for building air handlers are a viable solution, capable of detecting, diagnosing and correcting real faults. In the set of tests performed, a variety of temperature sensor faults were accurately detected, diagnosed, and corrected to within an accuracy of around $1^{\circ} \mathrm{F}$ (which should improve further with some of the recommended follow-on work). Relative humidity sensor faults were detected, diagnosed, and corrected to within 5-7\% $\mathrm{RH}$.

This set of tests has highlighted that the performance of rule-based automated fault detection and diagnosis (AFDD) is highly dependent both on the driving conditions and on the type of fault that exists. While certain faults are not readily detectible given certain outdoor- and return-air temperatures, this shortcoming simply implies time may be required for appropriate conditions to occur for faults to be detected. If a fault is not detectable under outdoor temperatures less than $70^{\circ} \mathrm{F}$, for example, this may just require that the system wait until the outdoor-air temperature falls within that range. In many cases, the fault may not have a significant impact on energy use or the performance of the air handler until such conditions occur. This, however requires further analysis.

The threshold for detecting temperature sensor bias faults with $2^{\circ} \mathrm{F}$ tolerances currently appears to be around 3 to $5^{\circ} \mathrm{F}$ for mixed-air sensors, 4 to $6^{\circ} \mathrm{F}$ for return-air sensors, and 8 to $15^{\circ} \mathrm{F}$ for outdoor-air sensors, when the outdoor-air damper is at minimum occupied position, with the exact value depending on the outdoor-air temperature. Minimum thresholds for detecting $\mathrm{RH}$ sensor faults appear to be in the $10 \%$ to $20 \%$ bias range, but the exact threshold is also likely strongly dependent on the specific air stream being measured and the outdoor and return-air conditions.

Critical to the implementation of self-correcting controls is the assurance that the algorithms will not detect, diagnose and correct a fault that does not exist (false positives), nor diagnose and correct the wrong fault (incorrect fault isolation or diagnosis). Such errors by self-correcting controls could cause more harm than good. At the current stage of development, more work is necessary to ensure that faults are diagnosed correctly and corrected accurately with a preference toward avoiding false positive fault detection. 


\section{Recommendations for Follow-on Work}

This section presents recommendations important for preparing self-correcting HVAC control technology for commercialization. The recommendations cover all aspects of develop: improvement of algorithms, additional laboratory testing, extending algorithms to other HVAC equipment and systems, field testing, analysis of potential impacts, and other needs.

\subsection{Changes to AFDD Algorithms}

Based on the discussion of test results in Section 5, several opportunities for improving the existing AFDD algorithms have been identified that would potentially make the algorithms more robust at detecting faults and more accurate in isolating and correcting faults. These changes are described briefly in Table 5 .

Table 5: Recommended changes to AFDD algorithms.

\begin{tabular}{|l|l|l|}
\hline Potential Change & Domain & $\begin{array}{l}\text { How the change might be } \\
\text { implemented }\end{array}$ \\
\hline $\begin{array}{l}\text { Account for damper } \\
\text { leakage }\end{array}$ & $\begin{array}{l}\text { Proactive diagnosis and } \\
\text { correction of } \\
\text { temperature sensor, } \\
\text { minimum occupied } \\
\text { position, and relative } \\
\text { humidity faults. May } \\
\text { have implications for } \\
\text { other dampers and } \\
\text { valves in HVAC } \\
\text { systems. }\end{array}$ & $\begin{array}{l}\text { Based on empirical evidence of non- } \\
\text { linear damper position vs. OAF behavior } \\
\text { (see Figure 7), develop a procedure for } \\
\text { automatically generating the OAF vs. } \\
\text { damper command curve, equations for } \\
\text { expected mixed-air temperatures during } \\
\text { proactive diagnostics, and a better } \\
\text { equation for fault correction that } \\
\text { incorporates the damper leakage. }\end{array}$ \\
\hline $\begin{array}{l}\text { Use a "full damper } \\
\text { range" prediction of OAF, } \\
\text { rather than just an } \\
\text { expected OAF at } \\
\text { minimum occupied } \\
\text { position. }\end{array}$ & $\begin{array}{l}\text { Detection of } \\
\text { temperature sensor and } \\
\text { minimum occupied } \\
\text { position faults during } \\
\text { economizing conditions. }\end{array}$ & $\begin{array}{l}\text { Based on empirical development of } \\
\text { damper position vs. OAF, develop } \\
\text { algorithms that automatically generate } \\
\text { equations for expected OAF for the full } \\
\text { range of damper positions, extending the } \\
\text { minimum occupied position passive test } \\
\text { to economizing conditions. }\end{array}$ \\
\hline $\begin{array}{l}\text { Enable detection of RH } \\
\text { faults when MA RH is } \\
\text { greater than OA RH and } \\
\text { RA RH, where possible }\end{array}$ & $\begin{array}{l}\text { Detection of RH sensor } \\
\text { faults. }\end{array}$ & $\begin{array}{l}\text { Develop a map of maximum mixed-air } \\
\text { RH, based on return- and outdoor-air } \\
\text { temperature and RH. }\end{array}$ \\
\hline
\end{tabular}




\subsection{Changes to Laboratory Test Apparatus}

The test apparatus, as it is currently configured has two key shortcomings that have limited the ability to control test conditions, and have thus far limited testing largely because of weather conditions.

First, to enable more flexibility in testing during the colder months, a method enabling heating of the raw outdoor air to higher temperatures before it enters the mixing box is needed. The cold air limits the ability to test fault detection and diagnosis at conditions close to room temperature. At times, testing must be shut down when the outdoor-air temperature approaches $0^{\circ} \mathrm{F}$, because anti-freezing controls on the indoor coils prevent operation. Heating could be accomplished by either installing an electric heater in the outdoor-air duct or installing a water heater that would provide hot water at a controlled temperature to a heating coil in the outdoorair duct. The second approach could use the coil that is already installed for pre-cooling the outdoor air. This coil could be used for heating and well as cooling with installation of the proper piping system. Addition of this pre-heating capability (along with the existing pre-cooling capability) would largely decouple testing from weather conditions and enable running of tests under cooling, heating or economizing conditions at nearly any time of year.

The second need relates to humidity sensor testing. The test environment could be enhanced to simulate more closely the conditions that exist in actual commercial buildings, especially in locations with humidity conditions other than the dry conditions of eastern Washington. The test apparatus, however, is located in a facility with no internal latent heat gain. The absolute moisture content of the return-air stream, therefore, is thus more or less equal at all times to the humidity of the outdoor air. This issue became pointed at times during the $\mathrm{RH}$ testing. During Test $\mathrm{RH}-1$, only sensibly heating of the outdoor air at $20^{\circ} \mathrm{F}$ and $30 \% \mathrm{RH}$ led to the return-air stream having only $3-5 \% \mathrm{RH}$. A solution might just be to add a simple humidifier to the room for winter testing.

\subsection{Testing Additional Faults Included in the Algorithm Set}

There are still a number of faults included in the original set of algorithms (see Fernandez et al. 2009) that have not yet been tested. These faults include

- Hard damper faults, like dampers stuck open, dampers stuck closed, and dampers that don't modulate fully open or fully closed. Both the correct detection of these faults when they occur and assurance that these faults don't cause false indications of other faults should be examined.

- Temperature sensor biases that are a function of time or temperature. Drifting sensors are common in HVAC equipment. Although the algorithms for sensor biases should in principle address sensor drift, this should be verified. Moreover, algorithms for sensor errors that depend on the magnitude of the measured quantity (e.g., temperature) should be developed.

- Highly noisy temperature sensors. SCC algorithms should be able to compensate for excess noise in sensors to minimize its delirious effects or to provide an alarm that a 
sensor with uncorrectable deleterious noise levels be replaced with analytic replacement of the sensor value until the replacement is made.,

- A series of faults occurring in sequence. This would include two or more of the same fault occurring over a period of time and different faults occurring sequentially.

- Hunting dampers.

The algorithms need to be tested to ensure they are able to detect these faults and perform the corrective action (even if that is just notifying the building operator of the fault).

\subsection{Additional Algorithms}

The current set of algorithms described in detail in Fernandez et al. 2009 cover only soft-faults in air-handler mixing boxes. The SCC capability should be expanded in to the following:

- SCC for other components of air-handling units, such as chilled-water valve control and discharge static pressure control, to complete the set of SCC algorithms for air-handling units.

- Development of SCC to compensate for hard faults until repair are made. The compensation would ensure that HVAC equipment and systems operate at peak efficiency in the presence of faults when they occur, until service or repairs are performed.

- SCC for air-distribution systems and VAV boxes.

- SCC for chilled- and hot-water distribution.

- $\quad$ Cooling tower SCC.

\subsection{Other Investigations}

- Additional lab testing to better understand and quantify behavior (e.g., limits of detectability and correction).

- Field testing to demonstrate SCC viability to stakeholders and to identify additional field deployment issues that are difficult to identify except with field tests.

- Integration of SCC with package unit controllers for retrofits of existing units and into packaged unit controllers for new equipment. This should be explored with package unit manufacturers.

- Integration of SCC into device controllers and/or field panels.

- Development of self-correction to other HVAC equipment, systems and integrated whole-building control. 
- Investigate other potential methods for fault detection and isolation that may overcome some of the limitations of the rule-based methods revealed in this study without requiring significantly greater numbers of sensors or data sampling rates.

- Investigate potential for model-free (generic) fault correction process.

- $\quad$ Study to quantify the benefits of various self-correcting HVAC controls.

- Development and evaluation of models for commercial deployment of the HVAC SCC technology.

In closing, exploration of interest by potential commercializers to bring them into development and testing activities as early as possible would likely accelerate deployment of SCC into commercial application. 


\section{References}

Ardehali, M.M. and T.F. Smith. 2002. Literature Review to Identify Existing Case Studies of Controls-Related Energy-Inefficiencies in Buildings, ME-TFS-01-007, Department of Mechanical and Industrial Engineering, The University of lowa, lowa City, IA.

Ardehali, M.M., T.F. Smith, J.M. House, and C.J. Klaassen. 2003. "Building Energy Use and Control Problems: An Assessment of Case Studies." ASHRAE Transactions, Vol. 109, Pt. 2, pp. 111-121.

Brambley, M.R., D. Hansen, P. Haves, D.R. Holmberg, S.C. McDonald, K.W. Roth and P. Torcellini. 2005a. Advanced Sensors and Controls for Building Applications: Market Assessment and Potential R\&D Pathways, PNNL-15149, Pacific Northwest National Laboratory, Richland, WA.

Brambley, M.R., D. Hansen, P. Haves, D.R. Holmberg, S.C. McDonald, K.W. Roth and P. Torcellini. 2005b. DOE Advanced Controls R\&D Planning Workshop, June 11, 2003, Washington, DC: Workshop Results, PNNL-15148, Pacific Northwest National Laboratory, Richland, WA.

Breuker, M.S. and J.E. Braun. 1999. "Common Faults and Their Impacts for Rooftop Air Conditioners." International Journal of Heating, Ventilating, and Air Conditioning and Refrigerating Research, 4(2):303-318.

Claridge, D.E., M. Liu, Y. Zhu, M. Abbas, A. Athar, and J.S. Haberl. 1996. "Implementation of Continuous Commissioning in the Texas LoanSTAR Program: Can You Achieve 150\% Estimated Retrofit Savings Revisited." In Proceedings of the 1996 ACEEE Summer Study on Energy Efficiency in Buildings. ACEEE, Washington, DC.

Du, Z. and X. Jin. 2007. "Tolerant Control for Multiple Faults of Sensors in VAV systems." Energy Conservation and Management 48(3):764-777.

Fernandez, N., M.R. Brambley and S. Katipamula. 2009. Self-Correcting HVAC Controls: Algorithms for Sensors and Dampers in Air-Handling Units, PNNL-19104, Pacific Northwest National Laboratory, Richland, WA.

Houghton, D. 1997. "Operating and Maintaining Rooftop Air Conditioners." ASHRAE Journal, 39(12):50-55.

Jacobs, P. 2003. Small HVAC Problems and Potential Savings Reports. P500-03-082-A-25, California Energy Commission, Sacramento, CA.

Jin, X. and Z. Du. 2006. "Fault Tolerant Control of Outdoor Air and AHU Supply Air Temperature in VAV Air Conditioning Systems Using PCA Method." Applied Thermal Engineering 26(11-12):1226-1237.

Katipamula, S., M.R. Brambley, N.N. Bauman, and R.G. Pratt. 2003a. "Enhancing Building Operations through Automated Diagnostics: Field Test Results." In Proceedings of the Third International Conference For Enhanced Building Operation, held October 13-15, 2003, Berkeley, California. Texas A\&M University, Energy Systems Laboratory, College Station, Texas. 
Katipamula S., M.R. Brambley, and L Luskay. 2003b. "Automated Proactive Commissioning of Air-Handling Units." PNWD-3272, Battelle Pacific Northwest Division, Richland, WA. Also published by the Air-Conditioning \& Refrigeration Technology Institute, Washington, DC. Available at www.arti-21cr.org/research/completed/finalreports/30040-final.pdf.

Katipamula, S., M.R. Brambley, and L. Luskay. 2003c. "Automated Proactive Techniques for Commissioning Air-Handling Units," ASME Journal of Solar Energy Engineering, Transactions of the ASME, Special Issue on Emerging Trends in Building Design, Diagnosis and Operation 125(1):282-291.

Katipamula, S. and M. R. Brambley. 2007. "Automated Proactive Fault Isolation: A Key to Automated Commissioning." ASHRAE Transactions, Volume 113, Part 2, pp. 40-51.

Lunneberg, T. 1999. "When Good Economizers Go Bad." ER-99-14, E Source, Boulder, Colorado.

Mills, E., H. Friedman, T., Powell, N. Bourassa, D. Claridge and M.A. Piette. 2004. The Cost Effectiveness of Commercial Buildings Commissioning: A Meta-Analysis of Energy and NonEnergy Impacts in Existing Buildings and New Construction in the United States. LBNL-56637, Lawrence Berkeley National Laboratory, Berkeley, CA.

Silva, P.M., V.M. Becerra, I. Khoo, and J.M.F. Calado. 2006. "Multiple-Model Fault Tolerant Control of Terminal Units of HVAC Systems." In IEEE International Symposium on Industrial Electronics (ISIE), vol. 4, pp. 2896-2901, July 9-13, 2006, Montreal, Quebec, Canada. Institute of Electrical and Electronic Engineers (IEEE), New York.

Steinberg, M. 2005. "Historical Overview of Research in Reconfigurable Flight Control." Proceedings of the Institution of Mechanical Engineers Part G: Journal of Aerospace Engineering 219(4):263-275.

Tomayko, J.E. 2003. The Story of Self-Repairing Flight Control Systems. Dryden Historical Study No. 1, National Aeronautics and Space Administration, Washington, DC.

Wang, S. and Y. Chen. 2002. "Fault-Tolerant Control For Outdoor Ventilation Air Flow Rate In Buildings Based On Neural Network." Building and Environment 37(7):691-704.

Xiaoli, H., Z. Guoqiang, and C. Youming. 2005. "Fault-Tolerant Control And Data Recovery In HVAC Monitoring System.” Energy and Buildings 37(2):175-180.

Xiong-Fu, L. and A. Dexter. 1999. "Fuzzy Model-Based Fault-Tolerant Control of AirConditioning Systems." In Proceedings of Building Simulation 1999, Paper B-06, IBPSA International Building Performance Simulation Association; available online at http://www.ibpsa.org/m bs1999.asp.

Xiong-Fu, L. and A. Dexter. 2001. "Fault-Tolerant Supervisory Control Of VAV Air-Conditioning Systems.” Energy and Buildings 33(4):379-389. 


\section{Appendix: Figures from Fernandez et al. 2009}

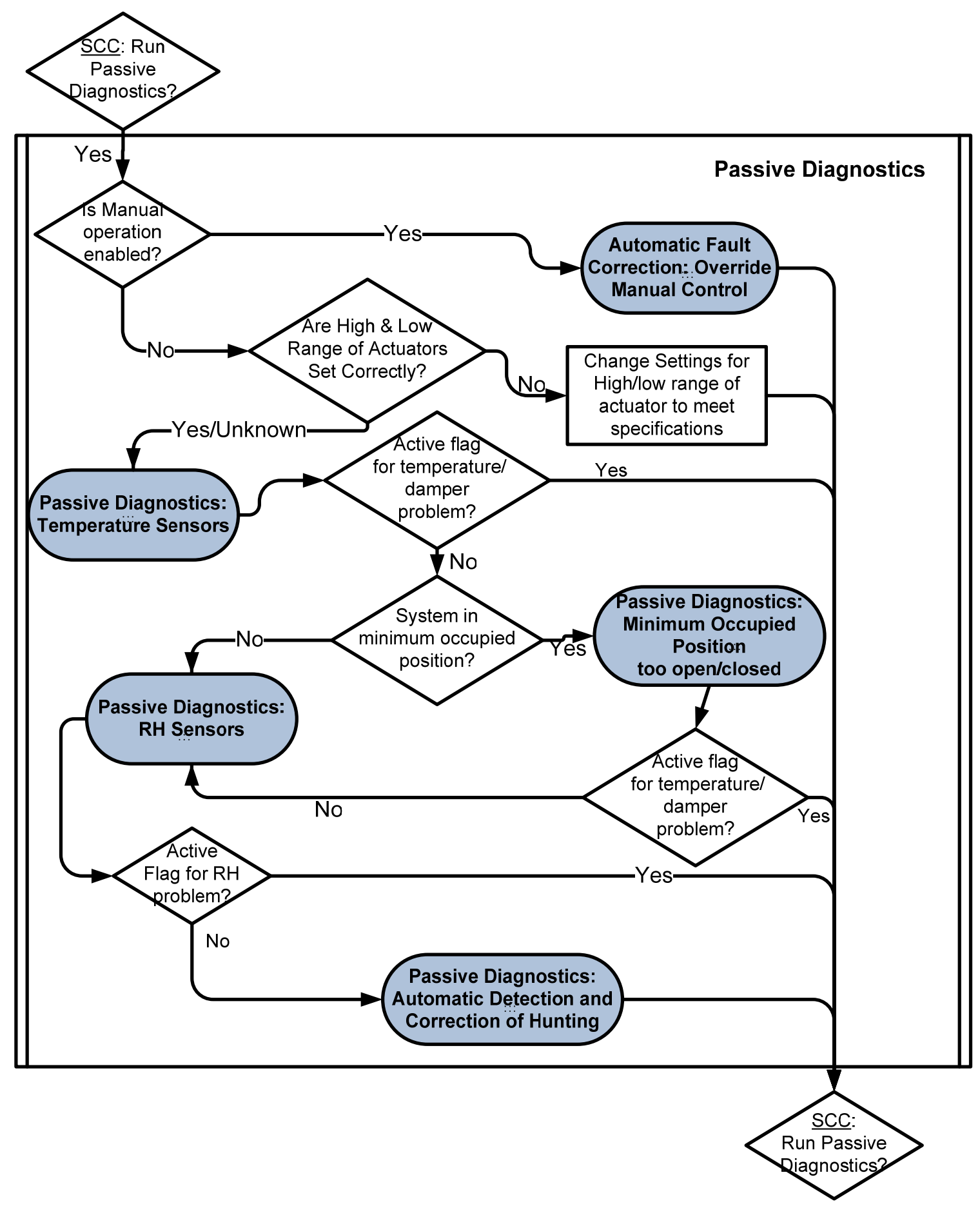

Figure 23: Summary Flowchart for Passive Diagnostics for Sensor and Damper Faults

${ }^{4}$ Figure numbers in this appendix are from Fernandez et al. 2009. 


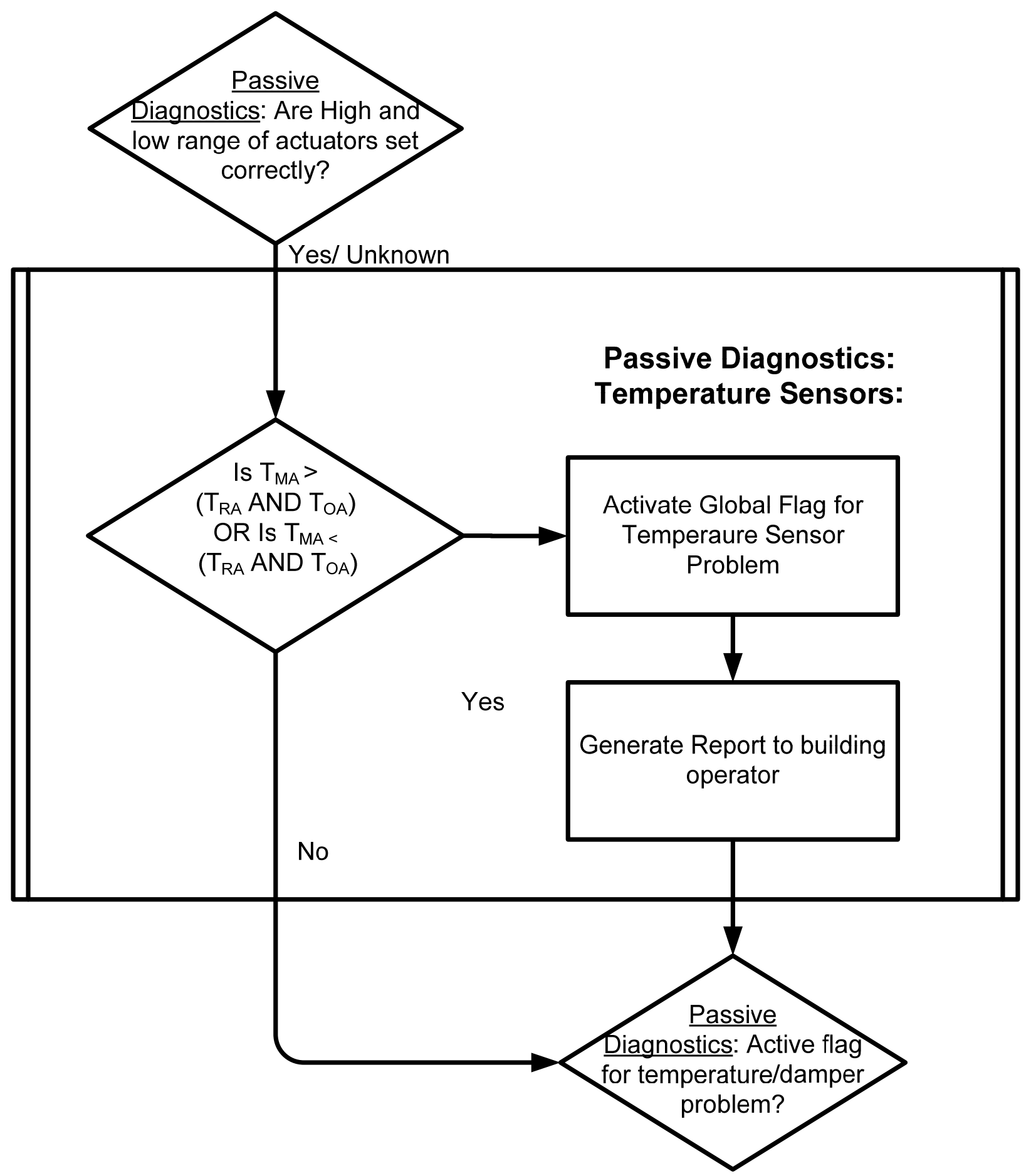

Figure 24: Passive Diagnostics for Detecting Temperature Sensor Faults 


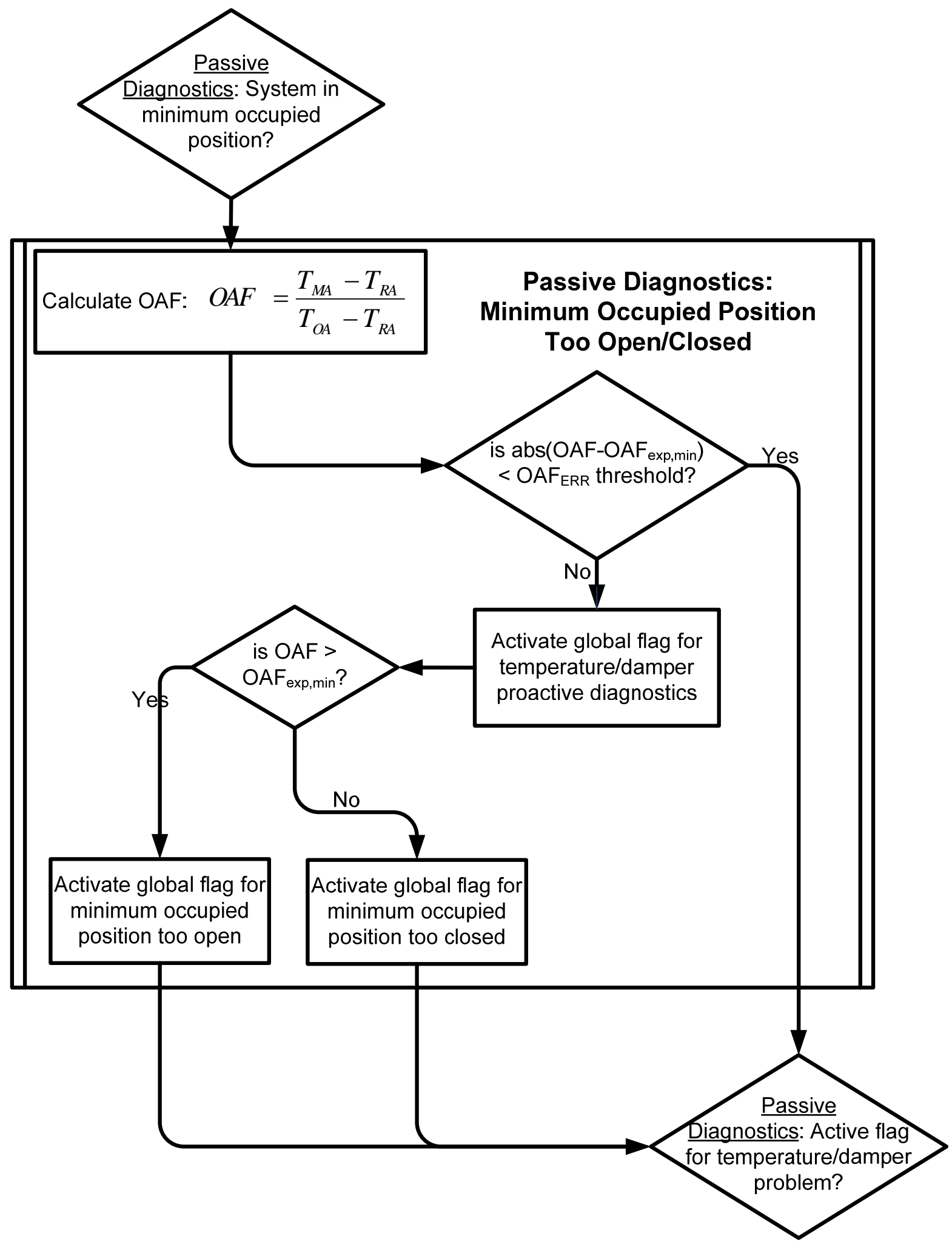

Figure 25: Flowchart for Passive Diagnostics for a Fault Associated with the Minimum Occupied Position Too Open or Too Closed 


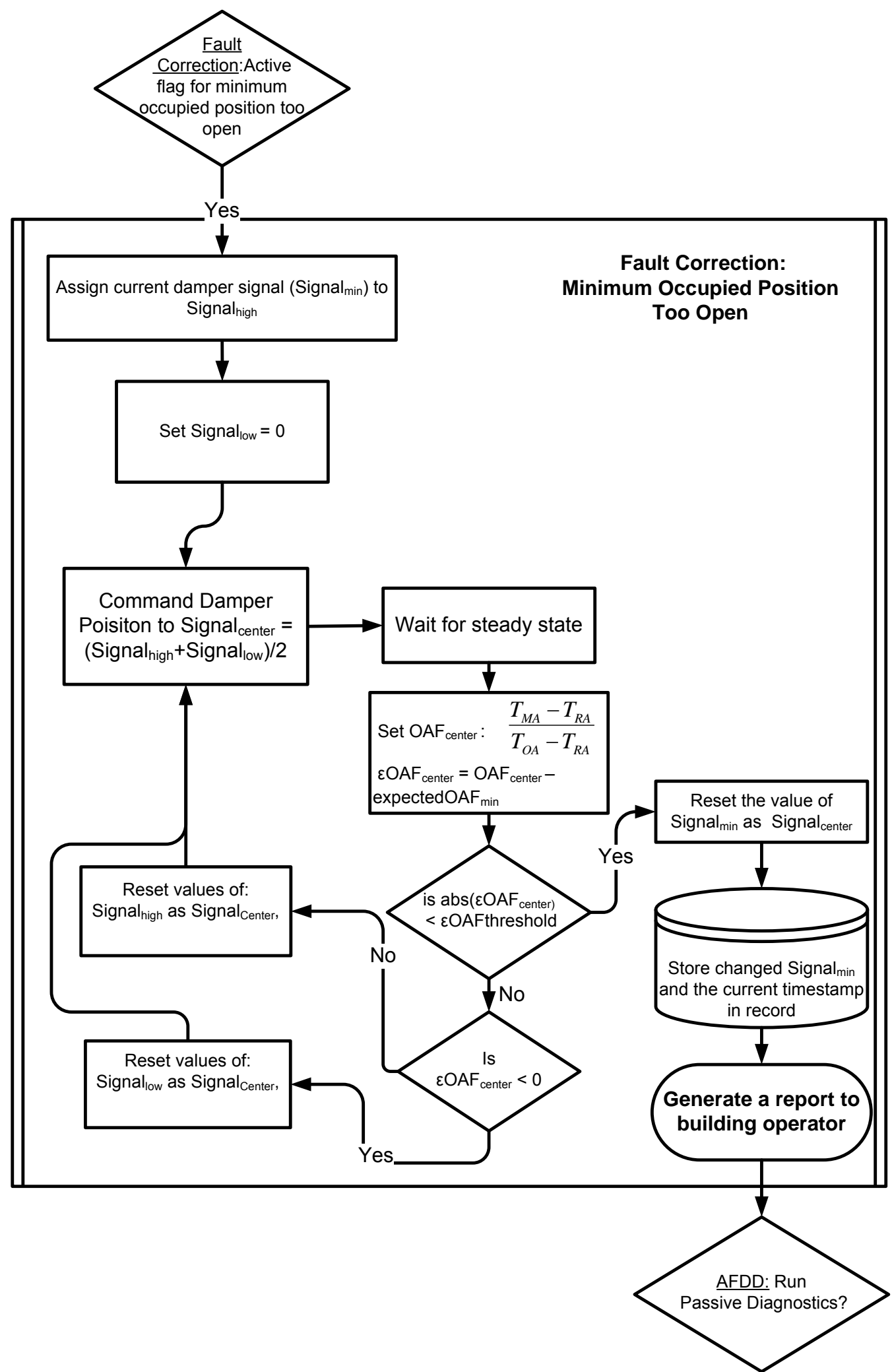

Figure 26: Flowchart for Correction of the Outdoor-air Damper Minimum Occupied Position Too Open 